\title{
La evaluación del desempeño en la normativa autonómica sobre función pública
}

Juan José Rastrollo Suárez

DOI: https://doi.org/10.47623/ivap-rvap.108.2017.13

\begin{abstract}
Sumario: I. Introducción.-II. La evaluación del desempeño en la normativa autonómica. II.1. Aragón. II.2. Principado de Asturias. II.3. Baleares. II.4. Castilla-La Mancha. II.5. Castilla y León. Il.6. Comunidad Valenciana II.7. Extremadura. II.8. Galicia. II.9. País Vasco.-III. Conclusiones.-IV. Bibliografía.
\end{abstract}

\section{Introducción}

La evaluación del desempeño fue introducida en el ámbito de la función pública estatal a través de la Ley 7/2007, de 12 de abril, del Estatuto Básico del Empleado Público, hoy convertido en Real Decreto Legislativo 5/2015, de 30 de octubre (en adelante TREBEP). Su Exposición de motivos la identificó como "elemento fundamental de la nueva regulación» llamado a introducir "un factor de motivación personal y de control interno" en consonancia las reformas que se habían emprendido en Europa, la misma venía a dar cumplimiento al principio de eficiencia en el seno de la Administración, incompatible con dispensar a todos los empleados el mismo trato sin tener en cuenta su rendimiento y su actitud ante el servicio. La evaluación aparece, además, ligada al principio de eficacia que, directamente vinculado a la cláusula de Estado Social, aparece en la Constitución Española como su vertiente instrumental(1),

(1) ARROYO JIMÉNEZ, L.: Libre empresa y títulos habilitantes, Centro de Estudios Políticos y Constitucionales, Madrid, 2004, pp. 186 y ss. 
y como principio general que debe aplicarse, sin distinción, a todas las Administraciones. (2)

Sin embargo, el carácter novedoso de la evaluación del desempeño solo es relativo. La misma cuenta ya con una dilatada historia en el seno de diversas administraciones $y$, por mucho que durante un tiempo se identificara la evaluación con una herramienta "neogerencialista» encaminada a la "empresarialización» de la función pública (3), sus orígenes se remontan en el tiempo mucho más allá de la década de los ochenta y su introducción en el ámbito de la Administración puede y debe encaminarse a su sostenibilidad, incrementado derechos como los de participación ciudadana o buena administración y principios como el de transparencia (4).

La primera experiencia en materia de evaluación del desempeño de empleados públicos estadounidenses de la que existe constancia es, muy posiblemente, la relativa a los militares estadounidenses que formaban parte del Departamento de Guerra durante 1813, sometidos a evaluación por parte de su general, que les otorgaba calificaciones en función del desempeño de sus tareas(5). Dicha experiencia se extende-

(2) Como puso de manifiesto, entre otras la Sentencia 85/1983, de 25 de octubre del Tribunal Constitucional. Véase, sobre el complejo proceso de incorporación del mismo a la Constitución, PAREJO ALFONSO, L.: "La eficacia como principio jurídico de actuación de la Administración Pública», Documentación Administrativa 218-219, 1989, pp. 15 a 66, que relata el proceso de incorporación del principio a la Norma Fundamental a lo largo del proceso de elaboración de la misma, "La eficacia, principio de la actuación de la Administración», en Eficacia y Administración. Tres estudios, INAP, Madrid, 1995, pp. 89 a 152. De las posibles formas de materialización del principio en el ámbito de la función pública ya ha dado cuenta el Tribunal Constitucional en diversos pronunciamientos. Así, el FJ3 de la STC 178/1989 de 2 noviembre declara, al referirse a la obligación de "dedicación exclusiva» de los funcionarios públicos, que el principio de eficacia «debe presidir, como es obvio, lo que es previo a la actividad administrativa, la "organización" y, en consecuencia, el aparato burocrático o, dicho de otro modo, el régimen de la función pública, entendida ésta en sentido amplio».

(3) En buena medida vinculada a diversos informes de la OCDE, entre los que puede consultarse Administration as Service: The Public as Client (1987) The Control and Management of Government Expenditure (1987) Flexible Personnel Management in the Public Service (1990) Public Management Developments: Survey 1990 (1990) Public Management Developments: Update 1991 (1991) Public Management Developments: Update 1992 (1992) Public Management Developments: Survey 1993 (1993) Private Pay for Public Work: Performance Related Pay Schemes for Public Sector Managers (1993) Public Management: OECD Country Profiles (1993) Pay Flexibility in the Public Sector (1993) o Performance appraisal: practice, problems and issues (1993), entre otros.

(4) En tal sentido puede hacerse referencia a la Ley 19/2014, de 29 de diciembre, de transparencia, acceso a la información pública y buen gobierno de Cataluña, que en conexión con otras normas autonómicas y el Estatuto de autonomía establece, complementando las medidas de buena administración, "un sistema de evaluación permanente de los servicios y con el reconocimiento del derecho de la ciudadanía a formular propuestas y sugerencias».

(5) BELLOWS, R.M. y ESTEP, M.F.: Employment Psychology: The Interview, Rinehart, New York, 1954, apud WIESEL, D. S. y BUCKLEY, M. R.: "The evolution of the performance appraisal process", Journal of Management History, Vol. 4 Iss 3, 1998 p. 235. 
ría a lo largo del siglo XIX, de forma progresiva y aislada, a diversos ámbitos de la Administración federal, en los que se comenzaría a utilizar el mecanismo de las calificaciones de mérito o índices de eficiencia en relación con la medición de la competencia, fidelidad o atención de los empleados públicos. Las calificaciones de los empleados, plasmadas en diversos informes, llegarían a ser requeridos por el Congreso estadounidense durante las décadas de los 40 y los 50 del siglo XIX (6). En el siglo XXI, tras diversas etapas de evolución a lo largo del siglo XX, la evaluación del desempeño sigue siendo habitual en diversas Administraciones estadounidenses. Objeto de una constante reinvención, algunas de las transformaciones que ha sufrido en las últimas décadas han ido encaminadas a dotarla de una mayor homogeneidad y a incrementar de las cotas de aceptación y de éxito en relación a los fines que pretende conseguir (7).

Por su parte, distintos países europeos han llevado a cabo profundos procesos de reforma de su función pública a lo largo de las primeras décadas del siglo XXI centrados, en gran medida, no tanto en la introducción sino en la "reinvención» de la figura(8). Es el caso de

(6) Concretamente a partir de 1842, como indican WHITE, L.D., The Jacksonians, The Macmillan Co. NewYork,1954 apud NYWIESEL, D. S. y BUCKLEY, M. R.: «The evolution...» op. cit. p. 235

(7) Aprovechando, por ejemplo, las ventajas de incorporar algunas características propias de la evaluación llevada a cabo bajo los parámetros del Total Quality Management, como indican NIGRO, LL. G. y KELLOUGH, J. E.: The new public personnel administration, Cengage, Boston, 2013, p. 159 o CONDREY, S. E.: "Public human resource management: how we get where we are today" en RICCUCCI, N. M.: (Dir.) Public personnel management. Current concerns, future challenges, Longman, Boston, 2011, pp. 23 y ss. En relación a la necesidad de simplificación de los sistemas de evaluación del desempeño pueden consultarse las conferencias de John BERRY, ex director de la United States Office of Personnel Management, como la ofrecida en la Maxwell School de la Universidad de Siracusa: https://www.opm.gov/news/speeches-remarks/a-merit-system-for-the-21st-century/ (consultado el 31 de octubre de 2016).

(8) A lo largo del siglo $x x$, diversas Administraciones europeas incorporaron mecanismos de evaluación de los empleados públicos. Por ejemplo, la notation, o calificación de los funcionarios, nació en Francia con el primer Statut général de la Fonction Públique de 1946. A partir del mismo se institucionaliza un sistema de calificación de los funcionarios públicos que seguiría vigente, sin grandes modificaciones, hasta el siglo XXI. En los mismos términos, se instauró el Rapporto informativo e giudizio complessivo por el artículo 42 del Testo unico delle disposizioni concernenti lo statuto degli impiegati civili dello Stato italiano de 10 de enero de 1957. La norma estableció la necesidad de emitir un informe motivado al final de cada año que debía hacer referencia a la calificación cada empleado estableciéndose que aquel empleado que hubiera sido objeto de una sanción disciplinaria durante el año no podía recibir una calificación superior a "buono». Sobre el primer estatuto general de la función pública francés véase GRÉGOIRE, R.:La fonction publique, A. Colin, Paris, 1954 y sobre la evolución de la relación estatutaria en la función pública francesa, véase ROUBAN, L.: Le statut des fonctionnaires comme enjeu socio-historique, Revue Française d'Administration Publique, 132, 2009, pp. 673 a 687. En relación a la evolución de la función pública en Italia desde la entrada en vigor del Estatuto Albertino hasta la fecha de publicación de dicha norma - con especial atención a los elementos que han singularizado el empleo público italiano, como la relevancia del Consejo de Estado- ORTEGA ÁLVAREZ, L. I.: «La función pública en el ordenamiento histórico italiano", Revista de Administración Pública 96, 1981, pp. 71 a 178. 
Francia (a través del Décret $n .^{\circ} 2010-888$ du 28 juillet 2010 relatif aux conditions générales de l'appréciation de la valeur professionnelle des fonctionnaires de l'Etat desarrollado por la Circulaire du 23 avril 2012, que contemplaría la aplicación de una nueva forma de evaluación, superando la tradicional notation desde el 1 de enero de 2012)(9), Gran Bretaña (a través del Civil Service Reform Plan de 2012), Italia (a través de la Legge 4 marzo 2009, $n .15$ che delega al Governo finalizzata all'ottimizzazione della produttività del lavoro pubblico e alla eficienza e trasparenza delle pubbliche amministrazioni nonché disposizioni integrative delle funzioni attribuite al Consiglio nazionale dell'economia e del lavoro e alla Corte dei conti, vinculada a la reforma Brunetta) (10) o Portugal (a través de la Resolução do Conselho de Ministros n. ${ }^{\circ}$ 95/2003, de 30 de julho y de la Resolução do Conselho de Ministros n. ${ }^{\circ} 53 / 2004$, de 21 de abril) (11).

En España pese a que las normas estatales no hacían referencia a un prístino sistema de evaluación que si existía en otros países como Francia (desde 1946) o Italia (desde 1957), el Decreto 316/1964 estableció la posibilidad de premiar a aquellos funcionarios que se distinguieran notoriamente en el cumplimiento de sus deberes a través de tres mecanismos: la mención honorífica, los premios en metálico y las condecoraciones y honores, con reflejo en la hoja de servicios del funcionario a tener en cuenta como mérito en los concursos (artículo 66) (12).

(9) Cuya interpretación y alcance deben complementarse con lo referido en la Circulaire relative aux modalités d'application du décret $n .^{\circ} 2010-888$ du 28 juillet 2010 relatif aux conditions générales de l'appréciation de la valeur professionnelle des fonctionnaires de l'Etat

(10) Véase BACCI, A., BUONAURO, C., CAROSI, A., CLARICH, M., De ANGELIS, L. M., MATTARELLA, B., NADDEO, A., PANOCCHIA, I. y VERBARO, F.: Il nuevo ordinamento del lavoro pubblico e il ciclo della performance, Promo P. A. Fondazlione, Lucca, 2010, pp. 181 a 193

(11) Véase MADUREIRA, C.: «Sistema integrado de avaliação de desempenho na administração pública portuguesa (SIADAP). Balanço de uma década", Lusíada. Economia \& Empresa. 20, 2015, pp. 171 a 194.

(12) Además se pretendía premiar la innovación, al establecerse la necesidad de consignar en los Presupuestos Generales del Estado créditos destinados a la concesión de premios para recompensar iniciativas y sugerencias en relación a la mejora de la Administración, "servicios eminentes" y todo mérito relevante o que redundara en una mejora de la eficacia administrativa. También es escasa la referencia en la norma de 1964 y en la Ley 31/1965, de 4 de mayo, sobre retribuciones de los funcionarios de la Administración Civil del Estado al reflejo de ese especial rendimiento en la masa salarial del funcionario, más allá de la definición recogida en el artículo 101. 4 de la Ley articulada, determinando que los incentivos remuneraban «un rendimiento superior al normal en el trabajo" y que se establecerían "cuando la naturaleza del servicio permita señalar primas a la productividad." Véase, sobre la historia del régimen retributivo de los funcionarios públicos en España previa a la entrada en vigor de la constitución NIETO GONZÁLEZ, A.: "La retribución de los funcionarios en España. Historia y actualidad», Revista de Occidente, Madrid, 1967 y, con posterioridad a la misma CASTILLO BLANCO, F.: "¿Es precisa una reforma del sistema retributivo de los funcionarios públicos? Una reflexión mirando a la historia.", Revista Española de Derecho Administrativo 112, 2001, pp. 493 a 532. 
Desde 2007 es el artículo 20 del actual TREBEP el que define la evaluación del desempeño como el procedimiento que -adecuándose a los criterios de transparencia, objetividad, imparcialidad y no discriminación - mide y valora la conducta profesional y el rendimiento o logro de resultados de los empleados públicos. Las escasas referencias que le dedica la norma estatal sirven para vincularlo a la carrera horizontal, identificando el resultado de la evaluación como uno de los criterios a valorar a la hora de determinar el grado de progresión del funcionario de carrera en la misma (artículo 17. b TREBEP), la provisión y mantenimiento de los puestos de trabajo y a la determinación de una parte de las retribuciones complementarias (artículos 22.3 y 24. c) TREBEP). Además, el Estatuto determina expresamente que las normas que fijan los criterios y mecanismos generales en relación con los procesos de evaluación del desempeño, son materia de negociación colectiva (artículo 37. 1. d) TREBEP).

\section{La evaluación del desempeño en la legislación autonómica sobre función pública}

A lo largo de las siguientes páginas hacemos referencia a determinadas Comunidades Autónomas que, bien han incorporado la figura de la evaluación del desempeño a su ley autonómica en materia de función pública (fundamentalmente por haber sido aprobada con posterioridad a 2007), o bien cuentan con un Reglamento relevante y con vocación de generalidad en el seno de la Administración, como ocurre en el caso Principado de Asturias. Además, recogemos la regulación de la evaluación del desempeño contenida en aquellos Anteproyectos y Proyectos de ley autonómicos en materia de función pública que incorporan la referencia a un sistema de evaluación (13).

\section{II.1. Aragón}

El Decreto Legislativo 1/1991, de 19 de febrero de la Diputación General de Aragón, por el que se aprueba el Texto Refundido de la Ley de Ordenación de la Función Pública de la Comunidad Autónoma de Aragón (TRLOFPA) hace referencia a diversas cuestiones vinculadas a la evaluación del

(13) Véase sobre la legislación autonómica en materia de función pública dedicada a la evaluación del desempeño ADIEGO SAMPER, C.: «Evaluación del desempeño. Un sistema integral» en VELÁZQUEZ LÓPEZ, F. J. y HERRERA DÍAZ-AGUADO, L. (Coords.): Cooperación en la formación entre instituciones, INAP, Madrid, 2015pp. 211 a 315 y PADILLA RUIZ, P.: Gestión del empleo público, Bosch, Barcelona, 2016, pp. 139 y ss. 
desempeño, sin que en la norma se dé una definición del mismo o se haga referencia expresa al procedimiento a seguir para llevarla a cabo(14). La Comisión es configurada como el órgano técnico de coordinación e información sobre la ordenación y gestión del personal (artículos 10 y 13). Llama en este sentido la atención, la falta de alusión expresa a la participación de los sindicatos o cualquier representante de los trabajadores.

El artículo 31. 3 TRLOFPA, por su parte, prevé legalmente una consecuencia en la relación de servicio derivada de una evaluación del desempeño de carácter negativo. Concretamente, hace alusión a la posibilidad de que el funcionario sea removido de su puesto de trabajo, obtenido por concurso, por ser su rendimiento notoriamente insuficiente «mediante resolución motivada, previa audiencia del interesado y oída la Junta de Personal que corresponda" (15). Complementando dicho pronunciamiento, el artículo 19 del Decreto 80/1997, de 10 de junio, por el que se aprueba el Reglamento de provisión de puestos, de trabajo, carrera administrativa y promoción profesional de los Funcionarios de la Administración de la Comunidad Autónoma de Aragón, matiza que el rendimiento insuficiente al que hace referencia la Ley aragonesa como causa de remoción no debe comportar inhibición e impedir realizar con eficacia las funciones atribuidas al puesto.

(14) Sí establece quién tiene la competencia en relación a su configuración, al reconocer en su artículo 12.2 c. la del Consejero de Presidencia y Relaciones Institucionales de Impulsar en relación a la coordinación y, en su caso, establecimiento y ejecución de los «planes, medidas y actividades tendentes a mejorar el rendimiento en el servicio, la formación y promoción del personal.» Por su parte, el artículo 13. 3. c) otorga a la Comisión Interdepartamental de la Función pública la competencia en relación a la formulación de propuestas orientadas a «la mejora de la organización, las condiciones de trabajo y el rendimiento del sistema de recursos humanos de la Comunidad Autónoma».

Como observaremos en páginas posteriores, la Comunidad Autónoma de Aragón viene trabajando durante algunos años en la reforma de su normativa en materia de función pública, haciéndose referencia en el Anteproyecto a la incorporación de sistemas de evaluación del desempeño en las Administraciones. Véase en este sentido RECIO SÁEZ DE GUINOA, J. M. y FERNÁNDEZ-CABALLERO LAMANA, L.: "Líneas generales de la nueva ley de empleo público de Aragón", Revista Aragonesa de Administración Pública 13, 2011, pp.65 a 95 y, más concretamente en relación con la incorporación del procedimiento objeto de nuestro estudio GORRITI BONTIGUI, M: "La evaluación del desempeño: análisis, retos y propuestas. Una aplicación a la Comunidad Autónoma de Aragón», Revista Aragonesa de Administración Pública 13, 2011, pp.297 a 320.

(15) De entre los mismos, son los que se encuentran en esta situación a consecuencia de la falta de rendimiento los únicos a los que no se les asegura, cuando no obtienen otro por los sistemas de concurso o libre designación, ser «adscritos provisionalmente a otro puesto propio de su Cuerpo, Escala y Clase de especialidad, con carácter preferente en el mismo área de especialización del puesto de procedencia, cuyo nivel de complemento de destino asignado no será inferior en más de dos niveles al de su grado personal consolidado, en la misma localidad y con el mismo régimen de dedicación, percibiendo las retribuciones complementarias del puesto suprimido o cuyo contenido haya sido alterado, salvo que puedan percibir otras superiores por el desempeño provisional de un puesto que las tenga atribuidas" (artículo 43. 2). Esta posibilidad se reserva únicamente para los trabajadores removidos por otras causas o cuyo puesto de trabajo se ha suprimido. Ello puede suponer un agravio comparativo no suficientemente justificado en la medida en que en la norma aragonesa con rango de Ley no se menciona el procedimiento a seguir para la evaluación ni se hace referencia a la formación como posible consecuencia de una evaluación negativa. 
Por su parte, el Anteproyecto de Ley de la Función Pública de Aragón incorpora interesantes novedades en la materia, introduciendo la gestión del rendimiento en la función pública aragonesa. En primer término, el artículo 6. 2. i) le atribuye al Gobierno de Aragón, a propuesta del Consejero competente en la materia, el establecimiento del sistema de gestión del rendimiento de acuerdo a lo establecido en la norma. A su vez, reconoce como competencia propia del Instituto Aragonés de Administración Pública en relación con los servicios y empleados públicos de la Comunidad Autónoma «La gestión del rendimiento de los empleados públicos, en el marco de su progresivo desarrollo profesional, conforme al sistema establecido para ello en la Administración de la Comunidad Autónoma» (10. 3. I).

El Capítulo III delTítulo III está íntegramente consagrado a la gestión del rendimiento vinculada, tanto a la carrera horizontal como a las retribuciones complementarias. En el mismo se determinan su concepto, su finalidad y sus efectos, así como su extensión al ámbito del personal directivo, que habrá de ser evaluado conforme a los criterios de eficacia, eficiencia, responsabilidad por su gestión y control de resultados y conforme a los objetivos fijados en la convocatoria del procedimiento para su designación (artículo 36). Tras introducir el deber de las distintas Administraciones de incorporar sistemas de gestión del rendimiento, la norma establece la necesidad de que contribuyan al desarrollo profesional, la mejora del rendimiento, la motivación, la formación y la adquisición de nuevas competencia, consagrando como criterios fundamentales a partir de los que desarrollarlos los de relevancia de los contenidos, fiabilidad de los instrumentos, transparencia, objetividad, imparcialidad y no discriminación, debiéndose aplicar con pleno respeto a los derechos de los empleados.

Como incorporación reseñable del Anteproyecto Aragonés está la referencia a las Comisiones de Garantías, órganos colegiados de carácter técnico encargados de conocer de las revisiones que los trabajadores soliciten en relación a los procesos de evaluación. Su composición y el resto de sus funciones se reserva al desarrollo reglamentario - no sin antes advertir de la necesidad de que sus miembros cumplan con los criterios de imparcialidad, idoneidad y profesionalidad-, determinando el quinto epígrafe del artículo 34 la necesidad de negociación previa al establecimiento de los criterios y mecanismos para la evaluación.

Respecto a los efectos de la evaluación, tan solo nos encontramos con la referencia a los ámbitos en los que pueden materializarse: promoción profesional, formación, provisión de puestos de trabajo, continuidad en el puesto y retribuciones complementarias de los empleados. No obstante, se consagra como efecto negativo el que no se tendrán en cuenta méritos de experiencia y antigüedad durante el periodo evaluado en procesos de selección, provisión y promoción profesional. 
El artículo 47. 5 incorpora la necesidad de tener en cuenta el cumplimiento del Código de Conducta en el apartado de valoración de la conducta del empleado. Por su parte, el artículo 92.1 b) establece que el rendimiento notoriamente insuficiente puesto de relieve a través de evaluaciones negativas del rendimiento, puede conducir a la remoción de los empleados que hayan obtenido un puesto de trabajo por concurso (artículo 111. 1. b). Además, se tienen en cuenta los resultados de la gestión del rendimiento para prolongar la permanencia en el servicio activo hasta los setenta años.

\section{II.2. Principado de Asturias}

Asturias es una de las Comunidades Autónomas que cuenta con un régimen jurídico más desarrollado en materia de evaluación, si bien dicho desarrollo se encuentra fundamentalmente en el ámbito reglamentario. No obstante, la Ley 3/1985, de 26 de diciembre, de Ordenación de la Función Pública de la Administración del Principado de Asturias (LOFPAS), define en su artículo 49 quáter (incorporado por Ley 5/2009, de 29 de diciembre, de séptima modificación de la Ley 3/1985, de 26 de diciembre, de ordenación de la Función Pública, para la regulación de la carrera horizontal) la evaluación del desempeño en los mismos términos en los que lo hace la norma básica estatal, determinando que los sistemas a implantar atenderán en todo caso a los principios marcados por el TREBEP. Este mismo artículo, incorpora la obligación de establecer dichos sistemas - que habrán de desarrollarse, como ha ocurrido, por vía reglamentariaen toda la Administración del Principado(16).

(16) En relación al ámbito competencial, es el artículo 15. 1 el que atribuye al Consejero de la Presidencia la función de «impulsar, coordinar $y$, en su caso, establecer y ejecutar los planes, medidas y actividades tendentes a mejorar el rendimiento del personal.» Como el resto de normas autonómicas que dedican parte de su articulado a la evaluación del desempeño, la norma asturiana destaca los efectos que puede tener sobre diversos aspectos de la relación de servicio la evaluación. En primer término cabe destacar la estrecha vinculación que el artículo 49. bis. 2 establece entre carrera horizontal y evaluación del desempeño, la cual se determina como uno de los méritos a valorar. En segundo término, debemos hacer mención al complemento de productividad, reconocido a los funcionarios como retribución complementaria destinada a retribuir el especial rendimiento (artículo $78.3 \mathrm{c}$ ). Por último, podemos destacar que la Ley asturiana reconoce expresamente la necesidad de someter a los directivos públicos -incorporados al ordenamiento jurídico asturiano a través de la Ley del Principado de Asturias 7/2014, de 17 de julio, de medidas en materia de función pública y organización administrativa - a evaluación en los mismos términos en que lo hace el TREBEP (artículo 8. bis. 2 LOFPAS) y que los artículos $91 . \mathrm{f}$ y 92 . c) tipifican como faltas muy graves o graves, respectivamente, la «notoria falta de rendimiento que comporte inhibición en el cumplimiento de las tareas" y "la disminución grave de rendimiento en la ejecución de los trabajos encomendados". Además, en relación al los directivos públicos, la norma de 2014 estableció como causa de cese a partir de la modificación del artículo 55. 1 la «Evaluación negativa del plan anual de objetivos de los titulares de los puestos directivos". 
Por su parte, el Decreto 37/2011, de 11 de mayo, por el que se aprueba el Reglamento de la carrera horizontal de los funcionarios de la Administración del Principado de Asturias consagra al procedimiento objeto de nuestro estudio su Título II, describiéndolo ampliamente. Pero, además, encontramos diversas referencias a la figura a lo largo del resto del articulado.

Lo primero que destaca es la consideración de la evaluación del desempeño como procedimiento que debe realizarse de forma individualizada y -como norma general- anualmente. Ello aunque se establezcan objetivos, tanto de carácter individual como de carácter colectivo (artículo 25 y 26 en relación con los artículos 46 y siguientes). Siguiendo la lógica establecida en la LOFPAS, se vinculan evaluación del desempeño y carrera horizontal (pues es necesaria la incorporación al sistema de progresión en la misma), estando dentro del ámbito subjetivo de aplicación del procedimiento los funcionarios de carrera de la Administración autonómica (incluyendo sus organismos públicos y entes públicos) en situación de servicio activo u otra que suponga reserva de plaza, y los de otras Administraciones que ocupen puestos en la Administración autonómica a partir de sistemas de concurso o libre designación (17).

La evaluación del desempeño en la Administración asturiana se realiza por el superior jerárquico y no por un órgano colegiado que aúne distintos intereses como en otras legislaciones (18). Debe tratarse, como norma general, de personal fijo. Sin embargo, también se contempla la posibilidad de que los altos cargos se conviertan en evaluadores, únicamente en el caso de que los evaluados presten servicios bajo su dependencia directa (19). Además de evaluador y evaluado, interviene un tercer actor en

(17) Por lo tanto, el ámbito de aplicación del reglamento es restringido: se reduce a la Administración autonómica y, dentro de la misma, a los funcionarios de carrera incorporados al sistema de progresión en la carrera horizontal. Se establece una última condición: el desempeño efectivo de los puestos de trabajo de forma continua o no durante al menos el $30 \%$ de su jornada laboral.

(18) La jurisprudencia ha dejado de manifiesto la necesidad de que el evaluador tenga unos conocimientos en cuanto a la actividad desarrollada reflejados en una titulación similar en resoluciones como las STSJ Madrid 901/2011 de 8 de noviembre o STSJ Andalucía (sede de Granada) 374/2016 de 15 de febrero, dejando de manifiesto la imposibilidad de que un diplomado en enfermería pueda ocupar el cargo de Director/a de la Unidad de Gestión Clínica (UGC) de Cuidados Críticos y Urgencias por llevar aparejado el cargo, entre otras, la función de evaluar el desempeño de la actividad desarrollada por el personal médico. El Tribunal Supremo reafirmó además el contenido de las primeras de las sentencias a través de la STS de 30 de mayo de 2014 (Recurso 2983/2012)

(19) Estos además, como resulta lógico, deben encontrarse en el ejercicio efectivo de su cargo cuando se produzca la evaluación pues en caso contrario se produce un vicio procedimental invalidante, como ha dejado de manifiesto la STS Madrid 10176/2009 de 18 de noviembre de 2009 (FJ 3). 
el proceso de evaluación: el superior jerárquico del evaluador, que será el encargado de aprobar el informe de evaluación definitivo en vista de la labor realizada por el evaluador y de las alegaciones presentadas por el evaluado (20).

Del articulado del Reglamento asturiano se desprende que las fases del procedimiento de evaluación previstas en la norma son las de: 1) Configuración de la unidad de evaluación en los términos anteriormente vistos, 2) Realización de la entrevista de evaluación 3) Realización de la evaluación en base a la técnica reglamentariamente establecida -que a continuación examinaremos-, 4) Remisión de la evaluación al responsable superior, 5) remisión de las alegaciones por parte de los evaluados al superior del evaluador, en su caso, 6) notificación de la evaluación a los funcionarios después de que la misma haya obtenido la conformidad del superior y, por último, 7) Proposición de acciones de mejora por parte del evaluador (en el supuesto de que se haya obtenido una evaluación negativa en el área de desempeño de tarea).

Una vez determinada la composición de las unidades de evaluación, será preciso llevar a cabo la entrevista. En ella, evaluador y evaluado intercambiarán pareceres, pudiendo los evaluados pronunciarse en relación a sus capacidades, la calidad del trabajo llevado a cabo o las condiciones laborales, apoyándose para ello, en su caso, en una memoria.

En el procedimiento de evaluación del desempeño recogido por el Reglamento Asturiano deben valorarse dos áreas: desempeño de tarea y desempeño contextual y organizacional. La primera de ellas hace referencia a la competencia con la que los evaluados desarrollan las actividades propias de su puesto de trabajo. La misma se concreta en una

(20) Estos tres tipos de actores componen lo que la norma asturiana define como unidad de evaluación: superior jerárquico del evaluador, evaluador (superior jerárquico de los evaluados) y evaluados, estando este último grupo conformado por el conjunto de funcionarios asignados a un determinado evaluador. La unidad viene determinada por la Consejería competente en la materia, a propuesta de las Secretarías Generales Técnicas de las distintas Consejerías y de las Direcciones o Gerencias de los organismos y entes públicos (artículo 39). Los funcionarios, evidentemente, tienen derecho a ser informados de la unidad de evaluación a la que pertenecen. Esta «jerarquización» de la evaluación del desempeño, que implica que la evaluación sea llevada a cabo por el superior jerárquico, se considera la más acertada para su implantación en las Administraciones públicas por algunos autores como GOITIRRI BONTIGUI, que en base a determinados estudios (fundamentalmente el de HUNTER, J.E. y SCMIDT, F.L. : Methods of metaanalysis: Correcting for error and bias in research findings, Sage, Newbury Park, CA 1990. Según afirma el autor) "la fiabilidad de las medidas es uno de los principales handicaps a la hora de implantar una ED en las AAPP. La fiabilidad habla de la consistencia interna del instrumento $(\alpha)$, estabilidad en el tiempo y grado de acuerdo entre evaluadores (fiabilidad interjueces). Si ya es un cambio cultural hacer una ED en las AAPP, más lo es hacerlo dos veces, preguntar a varios, preguntar lo mismo en distintos periodos de tiempo o a compañeros de trabajo (pares)." "La evaluación de desempeño en la Ley de Empleo Público de Castilla-La Mancha», Revista jurídica de Castilla-La Mancha, 50, 2011, p. 353. 
serie de dimensiones que varían en función del grupo al que pertenezcan los funcionarios evaluados(21). El segundo área se centra en las conductas o comportamientos del evaluado que «contribuyen a la eficacia de la administración ayudando al contexto social y humano, con actitudes que definen el ambiente del puesto de trabajo y sirven como catalizadores y facilitadores del desempeño de las tareas, propias y de otros, así como las conductas y acciones realizadas voluntariamente por los funcionarios que resultan relevantes para los legítimos intereses de la Administración". Las dimensiones vinculadas al mismo son similares para todos los trabajadores, con independencia del grupo al que pertenezcan. Concretamente, el artículo 34. 1 del Reglamento se refiere a las de orientación a objetivos y resultados, iniciativa, compromiso con la organización, colaboración y cooperación con compañeros, compartir y transmitir conocimientos, mantenimiento voluntario del rendimiento laboral, mantenimiento voluntario de la calidad del trabajo, uso adecuado del tiempo y los recursos laborales, asistencia al trabajo y uso eficiente del tiempo y ritmo voluntario eficiente del trabajo (22).

Cada una de las dimensiones debe valorarse en el informe en base a una escala que va de 1 a 4 , siendo negativas aquéllas evaluaciones de área que no superen el 2. Evidentemente es precisa su motivación en tal

(21) Así, para los funcionarios de los grupos A1 y A2, se contemplan la evaluación sobre las capacidades de toma de decisiones y organización planificación y resolución de problemas, además de evaluarse los conocimientos técnicos y la productividad, que la norma define como la cantidad y calidad de trabajo. Para los funcionarios de los grupos $\mathrm{C} 1$ y $\mathrm{C} 2$ y para las agrupaciones funcionariales, se contemplan las áreas de capacidad de aprendizaje, minuciosidad y responsabilidad, esfuerzo y perseverancia, conocimientos técnicos y productividad entendida en los mismos términos que en el caso anterior. Posiblemente, la necesidad de evaluar las mismas dos áreas en relación a todos los grupos de funcionarios, con independencia de que estas contemplen dimensiones diferentes, es un punto de rigidez que nunca debe ser excesiva en los procedimientos de evaluación del desempeño, como ha puesto de manifiesto NOGUER PORTERO, M. C. en "La evaluación del desempeño", en DEL REY GUANTER, S. (dir.). Comentarios al Estatuto Básico del Empleado Público, La Ley, Madrid, 2008 , pp. 303 a 326.

Sobre el valor ponderado de cada uno de los aspectos a valorar en los procedimientos de evaluación del desempeño desarrollados en la Administración pública asturiana véase SALGADO VELO, J. y LUIS CABRAL, A.: "Evaluación del desempeño en la Administración Pública del Principado de Asturias: análisis de las propiedades psicométricas", Revista de psicología del trabajo y de las organizaciones/ Journal of work and organizational psychology 2, 2011, pp. 75 a 91.

(22) Dicho de otra manera: si la primera de las áreas a evaluar hace referencia a la forma en la que el evaluado cumple las tareas asignadas a su puesto de trabajo, la segunda valora tanto la contribución del mismo al buen clima laboral y organizacional, como la innovación y creatividad que el funcionario demuestre en su desempeño, siempre que esta redunde positivamente en el funcionamiento de la Administración El anexo III lleva a cabo una descripción pormenorizada de las distintas dimensiones evaluables en las distintas áreas como capacidad de toma de decisiones, capacidad de organización y planificación o capacidad de resolución de problemas. La abstracción y generalidad de estos criterios fueron examinados por la STSJ Asturias de 17 de julio de 2012 que estimó parcialmente las pretensiones de la asociación Conceyu por otra función pública n'Asturies. 
caso (23). Una vez elaborado, debe darse traslado al funcionario para que lleve a cabo alegaciones en el plazo de tres días, que pueden ser tenidas en cuenta por parte del superior jerárquico del evaluador para modificar las puntuaciones obtenidas. Posteriormente, el superior jerárquico procederá a la elaboración del informe (que debe remitir tanto al superior como a la Dirección General competente en materia de evaluación de recursos humanos con la conformidad del anterior), ello con anterioridad al 20 de diciembre de cada año.

Si existe disconformidad con el contenido el informe, el funcionario tiene la posibilidad de recurrir ante la Comisión de Revisión, que se configura como órgano competente para conocer de las solicitudes interpuestas por los funcionarios a consecuencia de su disconformidad con el contenido del informe emitido por su evaluador(24).

\section{II.3. Baleares}

La Exposición de motivos de la Ley 3/2007, de 27 de marzo, de la Función Pública de la Comunidad Autónoma de las Illes Balears, (LFPIBAL) en su epígrafe primero ya hace referencia a la, denominada en Baleares, evaluación del rendimiento, como uno de elementos estratégicos a partir de los cuales conseguir los objetivos de profesionalizar y modernizar la función pública autonómica, mejorando asimismo la calidad del servicio

(23) Cabe poner de manifiesto en este punto que, además de la inseguridad jurídica que puede derivarse de la excesiva abstracción, generalidad y falta de concreción que puede resultar inherente a algunos de los criterios establecidos por la legislación para proceder a la valoración, es necesario que los mismos hagan referencia a objetivos que den alguna medida dependan del evaluado. En este sentido, el Procedimiento Abreviado n. ${ }^{\circ}$ 268/11 del Juzgado de lo Contencioso Administrativo n. ${ }^{\circ} 1$ de los de Gijón, que dio la razón a un funcionario que entendía que no procedía evaluar determinados indicadores (número de servicios no incendios y números de incendios a los que acudió) por ser ajenos a su desempeño habitual y no gozar de transparencia, objetividad, transparencia y no discriminación. No obstante, la STS Asturias 90321/2012 de 24 de octubre de 2012 dio la razón al Ayuntamiento en apelación.

Sobre la relevancia de tener en cuenta en el proceso evaluador los méritos con la mayor validez predictiva véase BASOREDO LEDO, C. y LÓPEZ BASTERRA, J.: «Bases de un modelo de evaluación de méritos profesionales en la administración pública centrado en el desempeño" Pertsonak eta Antolakunde Publikoak Kudeatzeko Euskal Aldizkaria/Revista Vasca de Gestión de Personas y Organizaciones Públicas 5, 2013, pp. 8 a 19.

(24) Esta se define en el artículo 43 del reglamento como un órgano colegiado de carácter técnico y permanente. Su presidente es el Director General competente en materia de evaluación del desempeño, estando conformada además por el titular de la Inspección General de Servicios, un letrado del servicio jurídico del Principado, el titular del servicio competente en materia de evaluación del desempeño, el titular del servicio competente en materia de administración de personal y un secretario, funcionario de carrera de la Dirección General competente en materia de evaluación del desempeño. Además de de conocer de las solicitudes derivadas de la disconformidad de los funcionarios evaluados en relación con el informe emitido, la Comisión conoce de cualquier queja formulada en relación al procedimiento, de la aplicación de los criterios que deben regir el procedimiento o de emitir un informe anual en relación con el conjunto de quejas planteadas. 
público. En el ámbito competencial, la norma balear atribuye al consejero o consejera competente en materia de función pública las funciones de impulso, coordinación y ejecución - en su caso- de planes y programas tendentes a la mejora del rendimiento (si bien esta función se atribuye a los consejeros competentes en materia de función pública docente y sanitaria en relación al ámbito particular de sus competencias). Asimismo, el artículo 10. 3 le atribuye a la Inspección General de Calidad la supervisión de la aplicación de estos sistemas. Además $-y$ esto es una novedad con respecto al resto de normas autonómicas - reconoce expresamente la vinculación que puede darse entre instrumentos de ordenación de planificación de distinto tipo referenciados en la norma y el resultado de los distintos sistemas de evaluación (artículo 38.4 y disposiciones adicionales tercera y cuarta).

La norma balear hace alusión expresa a un necesario desarrollo reglamentario posterior (artículo 39) pero en este precepto, consagrado al procedimiento objeto de nuestro estudio en la LFPIBAL, determina expresamente que las Administraciones de las Islas deben implantar progresivamente sistemas de evaluación del cumplimiento, vinculándolo a la mejora de la motivación, del rendimiento y de la calidad de los servicios. El artículo 39 hace además alusión a que dichos procedimientos son públicos y sus resultados deben ser objetivos e imparciales (lo cual se reconoce expresamente como derecho del empleado público en el artículo 115. 1. f), estableciendo, además, que el resultado de los mismos tendrá efecto en la carrera y en la determinación de retribuciones complementarias. Se citan como elementos a tener en cuenta a la hora de llevar a cabo la evaluación tanto los resultados, como los comportamientos y conductas y proyectos implantados o ejecutados.

Respecto a las consecuencias de una evaluación negativa, la norma balear contempla la posible finalización de la comisión de servicios (artículo 88. Ter. 2. d) o la remoción del puesto de trabajo obtenido por concurso (artículo 92. 1. a). Por su parte, el complemento de productividad que se vincula directamente a la obtención de una evaluación del rendimiento positiva (39. 2) se configura como una retribución complementaria que "retribuye la especial dificultad técnica, la responsabilidad, la dedicación o la incompatibilidad que concurren en determinados puestos de trabajo, o las condiciones especiales en las que se ejercen las funciones", reconociéndose de forma expresa tan solo a funcionarios de carrera.

En relación a los efectos positivos sobre la carrera, el artículo 64 c) cita expresamente la adquisición del grado personal por procedimientos de evaluación del rendimiento. Además, cabe destacar de la LFPIBAL liga expresamente, como hace el TREBEP, la continuidad en el puesto del directivo profesional al resultado positivo de la evaluación (artículo 35) y men- 
ciona entre las faltas muy graves y graves la falta notoria de rendimiento en los artículos 137 h) y 138 i).

\section{II.4. Castilla-La Mancha}

Castilla-La mancha es una de las Comunidades Autónomas que cuenta en su norma general sobre función pública con uno de los regímenes jurídicos más completos en materia de evaluación del desempeño. Ya la Exposición de motivos de la Ley 4/2011, de 10 de marzo, del Empleo Público de Castilla-La Mancha, (LEPCM), presenta la regulación de los sistemas de carrera y promoción profesional, provisión de puestos de trabajo y movilidad a lo largo de los Títulos V y VI en una doble vertiente: como un derecho a la progresión individual de los destinatarios y como un usistema ordenado y orientado a la mejora en la prestación de servicios públicos», centrada por tanto en los ciudadanos. Afirma además la Exposición, que la evaluación del desempeño se concibe como principio informador vinculado a la responsabilidad en la gestión con un carácter transversal (por afectar, según afirma, a la práctica totalidad de los aspectos que rodean el empleo público) y permanente en el tiempo, por ser un instrumento encaminado a la mejora constante del empleo público autonómico.

El artículo 66 LEPCM está consagrado a la evaluación del desempeño. El segundo de sus epígrafes contiene una definición de la misma que no se separa un ápice de la contenida en el artículo 20TREBEP. El artículo establece, además, que la puesta en marcha de procedimientos de este tipo es un deber para las Administraciones públicas de la Comunidad. A la hora de determinar los criterios que deben regir el desarrollo del procedimiento la LEPCM, después de citar expresamente los referidos en la normativa estatal, hace alusión a la discrecionalidad técnica que en todo caso estará presente en el proceso y a la exigencia de que esta se aplique sin lesionar los derechos del personal funcionario(25). Es elogiable la re-

(25) Respecto a las Comisiones de valoración en el ámbito de la evaluación del desempeño, cabe advertir que la jurisprudencia se ha pronunciado sobre los márgenes de discrecionalidad técnica entre los que debe producirse la actuación de las mismas, así la STSJ Andalucía (Sede de Granada) 1608/2013, de 6 de mayo, se pronunció dejando de manifiesto que «No se discute por ser reconocida por ambas partes la facultad discrecional de la Comisión de valoración, como órgano técnico especializado cuyos conocimientos técnicos son necesarios para la individualización y distribución del complemento a cada funcionario que en este caso concreto son los que poseen los distintos jefes de servicio, especialmente designados para formar parte de la misma por su capacidad de valoración individual en la percepción diaria, personal, inmediata y directa del trabajo de los funcionarios a su cargo. Los principios generales no son más que los grandes parámetros que deben guiar su evaluación. Sin embargo, es importante determinar cual sea el margen preciso de esa indiscutible facultad discrecional que escapa a cualquier control judicial por ser solo ellos los que ostentan ese conocimiento referido a la percepción inmediata y continua del trabajo y esfuerzo de cada funcionario de su ámbito. Y lo que en definitiva constituye su ámbito discrecional es el margen de valoración 
ferencia expresa que la norma hace a la necesidad de que, con carácter previo al desarrollo de los sistemas de evaluación, se lleve a cabo un análisis y descripción de puestos de trabajo en las que se haga referencia a sus funciones y sus estándares e indicadores de rendimiento (información que debe estar a disposición de quienes ocupen el puesto de trabajo en el momento de su incorporación a la función pública) (26).

La norma hace una referencia expresa a los factores que, como mínimo, habrán de tenerse presentes para llevar a cabo la evaluación. Se trata de conceptos jurídicos indeterminados que adolecen de cierta vaguedad en su definición, e incluso en algunos supuestos de falta de conexión con el objeto de los procedimientos (27).

En relación a los órganos que llevarán a cabo la evaluación, el artículo 66. 6 permite que formen parte de los mismos personas superiores jerárquicamente, personas jerárquicamente dependientes o personas sin relación de jerarquía. En todo caso, lo que sí se establece expresamente es que estas deberán constituir un órgano colegiado del que deben formar parte los sindicatos integrantes de la mesa de negociación correspondiente al ámbito del personal evaluado. Este órgano colegiado, además de funciones de evaluación, tiene como labor la proposición de medidas de revisión y control para la mejora del procedimiento y la competencia para resolver los recursos presentados frente las resoluciones relativas a la misma, sustituyendo a los ordinarios regulados en la LPA(28).

\footnotetext{
y decisión en la atribución o no a cada funcionario de los cinco criterios predeterminados legalmente (...) ahora bien, (...) lo que si le vincula es el uso de los mismos y no otros criterios, así como la puntuación que deba corresponder a cada uno y esto sí deberá expresarse y es controlable por constituir un hecho determinante por ser circunstancias de hecho previstas en la norma aplicable, que deben aplicarse y consignarse pues en caso de no hacerlo se incurrirá en arbitrariedad o en un resultado de agravio comparativo" (FJ 7).
}

(26) No obstante, la relevancia que puede tener dicha aseveración se limita considerablemente, toda vez que no existe ninguna referencia expresa en la Ley al procedimiento a partir del cual se puede llevar a cabo el análisis (o al menos a los elementos esenciales del mismo), que se configura fundamento del sistema de evaluación a partir del cual pueden verse condicionados los derechos y obligaciones del empleado público, ni a cómo se pueden o deben determinar los estándares de rendimiento o a cuál debe ser su contenido. Además, entendemos que la información relativa a las cuestiones anteriormente mencionadas debería estar, en virtud del principio de transparencia expresamente enunciado en relación a los sistemas de evaluación, a disposición de todos los ciudadanos y no solo de los trabajadores públicos.

(27) Concretamente los de: a) Grado de cumplimiento de los estándares de rendimiento del puesto de trabajo. b) Cumplimiento de objetivos y metas de carácter colectivo. c) Responsabilidad y autonomía que se asume en el puesto. d) Actitud en la organización y trabajo en equipo. e) Orientación a las personas destinatarias del servicio. f) Creatividad e iniciativa. g) Competencia personal (artículo 66. 5)

(28) Lo que critica, entendemos que acertadamente GORRITI BONTIGUI cuando afirma que «preocupante es cuando en el Art. 66.7. incluye a las organizaciones sindicales en los órganos colegiados para la revisión y análisis de las ED realizadas y para resolver las reclamaciones...La ED es esencialmente un proceso técnico, pero muy susceptible de contaminaciones si esta técnica se obvia.", Véase "La evaluación de desempeño en la Ley de Empleo Público de Castilla-La Mancha», Revista jurídica de Castilla - La Mancha, 50, 2011, p. 365. 
Además, el artículo 151. 1. d) reconoce la evaluación del desempeño como materia de negociación colectiva (en relación con las competencias de cada Administración y con el alcance que legalmente proceda) y el artículo 163. f) le otorga a la Comisión de coordinación del empleo público de Castilla-La Mancha la función de promover medidas de cooperación y asistencia técnica. Ello con el fin de solucionar las carencias que, en razón de su dimensión, puedan tener algunas Administraciones públicas autonómicas en relación con los sistemas objetivos de evaluación del desempeño (29).

El resto de epígrafes y artículos se consagran a la determinación de los efectos de la evaluación del desempeño en muy distintos aspectos. A la obtención de una evaluación positiva se vinculan las retribuciones complementarias (artículo 85. 1), expresamente reservadas a los funcionarios públicos y de las que se excluye de forma explícita al personal eventual (artículo 92.4), el reconocimiento de los tramos para la progresión en la carrera horizontal $(64.6 \mathrm{c}$ ) o la obtención de un puesto de trabajo a través del procedimiento de concurso, teniéndose como mérito evaluable los resultados positivos obtenidos en la evaluación del desempeño, a los que obligatoriamente debe referirse la convocatoria (artículo 68. 7).

La obtención de una evaluación negativa se vincula asimismo a muy variados aspectos, tales como la denegación de la prolongación de la permanencia en el servicio activo hasta la edad máxima de jubilación (artículo 60. 4. b), el no reconocimiento del periodo de tiempo evaluado como experiencia en procedimientos de provisión y los procesos selectivos convocados por los sistemas de concurso-oposición, concurso o designación de personal directivo profesional (artículo 66.8), la remoción del puesto de trabajo obtenido mediante concurso (artículo 69.1) o el deber de formación (artículo 112).

\section{II.5. Castilla y León}

El sistema de evaluación del desempeño recogido en la legislación autonómica en materia de empleo público de Castilla y León, tiene como particularidad que solo está dirigido a los puestos directivos y unidades con rango igual o superior a la jefatura de servicio que integran la Admi-

(29) Se trata este último de un órgano colegiado de carácter técnico (muy similar al previsto en el ámbito estatal por el artículo 100 TREBEP) que, regulado por la Orden de 14 de diciembre de 2011, de la Consejería de Presidencia y Administraciones Públicas, por la que se constituye la Comisión de Coordinación del Empleo Público de Castilla-La Mancha, tiene como finalidad coordinar las políticas en materia de empleo público en la Comunidad Autónoma en el que están presentes representantes de las Administraciones autonómica y local, pero no de las organizaciones sindicales. 
nistración autonómica(30). Así lo establece el artículo 70, Ley 7/2005, de 24 de mayo, de la Función pública de Castilla y León (LFPCyL). Ello implicará que los efectos positivos y negativos derivados de la misma se proyectarán exclusivamente sobre los empleados públicos de mayor rango (y por lo tanto, en algunos casos, especialmente cercanos a los dirigentes políticos).

En tal sentido cabe recordar que el artículo 48. 2. b) de la norma casteIlano y leonesa prevé que la libre designación "constituye el sistema excepcional de provisión de puestos de trabajo, mediante el cual podrán proveerse los puestos iguales o superiores a Jefes de Servicio y los de Secretarías de Altos Cargos, así como aquellos otros que, por la importancia especial de su carácter directivo o la índole de su responsabilidad, y en atención a la naturaleza de las funciones, se determinen en las relaciones de puestos de trabajo». (31)

La norma castellano y leonesa hace referencia tanto a la periodicidad con la que debe efectuarse el procedimiento, como a los principios que tienen que regir el proceso y los elementos que deben ser valorados. En relación a la primera de las cuestiones, se determina que la evaluación tendrá un carácter anual. En relación a la segunda, se mencionan, a parte de los expresamente referidos en el TREBEP, los de igualdad -lo cual parece contradecir el rasgo más significativo del sistema castellano y leonés-, mérito, capacidad, eficacia administrativa y seguridad jurídica (32).

En relación a la tercera cabe destacar que la norma determina que, para llevar a cabo la evaluación, se tiene en cuenta la cantidad y calidad del trabajo realizado en base a dos parámetros: «a) La organización de la unidad sometida a evaluación, o de las unidades sobre las que despliega sus efectos el puesto directivo en el caso de ser éste el sometido a evaluación, y el resultado obtenido en relación con los medios personales y materiales de que se dispone así como en relación con los objetivos propuestos" y «b) La capacidad organizativa así como las propuestas y mejoras introducidas en la unidad y en su funcionamiento a instancia de su

(30) Si bien esto resulta contradictorio, no solo con la efectiva proyección del principio de eficacia en el seno de la Administración, sino con lo determinado por diversas normas internacionales sobre la gestión de calidad, como la norma ISO 9001:2000 o la norma 220 de la Federación Internacional de Contabilidad. Véase en este sentido FOMBELLIDA ARAGÓN, R.: La gestión de personas a través del desempeño de competencias, Auditoría Pública 43, 2007, pp. 40 y ss.

(31) Existe una excepción en relación al personal estatutario médico, respecto al cual la Ley 2/2007, de 7 de marzo, del Estatuto Jurídico del Personal Estatutario del Servicio de Salud de Castilla y León liga desarrollo profesional y evaluación del desempeño en distintos artículos.

(32) La proyección del principio de transparencia en el procedimiento, presente también en la legislación básica en la materia, implica necesariamente poner a disposición del trabajador evaluado información sobre el desarrollo del procedimiento de evaluación. Si esta puesta a disposición se negase o dificultase el procedimiento no sería conforme a dicho principio, como deja de manifiesto la STSJ Andalucía (Sede de Granada) 1608/2013, de 6 de mayo (FJ7) 
titular. En el supuesto de evaluación de puestos directivos, la capacidad de dirección, organización y mejora de las diferentes unidades y funciones comprendidas en su ámbito de actuación introducidas a instancia del titular del puesto directivo".

De esta manera, se deja aún más de manifiesto la particularidad característica de la regulación del sistema de evaluación del desempeño de la función pública castellano y leonesa, exclusivamente dirigido a la evaluación de cargos directivos (artículo 70. 2 LFPCyL). Se determina, además, por vía legal el órgano que tendrá que llevar a cabo la valoración que no es otro que una Comisión de Evaluación del Desempeño, creada por Decreto de la Junta. (33)

Por último, la norma castellano y leonesa, establece las consecuencias aparejadas a la evaluación del desempeño: en un sentido punitivo, el artículo 50. 5 establece la posibilidad de remover al funcionario que acceda a su puesto de trabajo por el procedimiento de concurso, entre otras casusas, "por una falta de capacidad para su desempeño manifestada por rendimiento insuficiente, que no comporte inhibición y que impida realizar con eficacia las funciones atribuidas al puesto». En todo caso, dicha sanción solo puede imponerse previo expediente contradictorio y mediante resolución motivada del órgano que le nombró, oída antes la Junta de Personal. Además, los artículos 81 y 82 identifican la falta de rendimiento como falta grave o muy grave en función de la incidencia que tenga en el funcionamiento de los servicios. Como recompensa, en el supuesto de una evaluación positiva, dentro de las retribuciones complementarias (reconocidas únicamente a funcionarios públicos) se hace una referencia expresa al complemento de productividad que, entre otros conceptos, retribuye el especial rendimiento - al que separa como concepto del interés e iniciativa demostrados-(34).

(33) La Comisión está formada por un mínimo de cinco miembros, siendo nombrado uno de ellos a propuesta de las Centrales Sindicales presentas en la Mesa General de negociación, que deben actuar de forma independiente en el desempeño de sus funciones. Respecto al procedimiento, la norma castellano y leonesa establece la necesidad de emitir la evaluación previa audiencia del evaluado, dándole traslado a la misma con posterioridad a la Dirección General de Función Pública y al órgano directivo al que se encuentre adscrita la Inspección General de Servicios (artículos 70. 3 y 70. 4 LFPCyL).

(34) En el ámbito reglamentario es preciso tener en cuenta, si bien en un aspecto prácticamente anecdótico, lo expresamente previsto por el Decreto 67/1999, de 15 de abril, por el que se aprueba el reglamento de ingreso y provisión de puestos de trabajo de los funcionarios de Castilla y León o el Decreto 213/1991, de 18 de julio, por el que se aprueban las normas reguladoras de la carrera administrativa de los funcionarios. El primero hace referencia en su artículo 60 a la posible remoción del funcionario que acceda por concurso a un puesto de trabajo. El segundo en su artículo 3 a que «El desempeño del puesto de trabajo con carácter provisional no se computa a efectos de adquisición del grado personal». 


\section{II.6. Comunidad Valenciana}

La Ley 10/2010, de 9 de julio, de la Generalitat, de Ordenación y Gestión de la Función Pública Valenciana, (LOGFPV), es una de las normas autonómicas que con más profundidad y de manera pionera ha abordado el régimen jurídico de la evaluación del desempeño a nivel autonómico. Ya su Preámbulo identifica la misma como una de las novedades más relevantes en el nuevo modelo de la función pública valenciana. Según el mismo, dichos sistemas se orientan a la mejor gestión de las administraciones, al control y reducción del absentismo, al progreso y desarrollo profesional y a la motivación de los empleados, a partir de su implicación en los objetivos fijados (35).

El artículo 121, bajo el epígrafe "evaluación del desempeño» establece la obligación de que las Administraciones implanten sistemas para su medición teniendo en cuenta, tanto la valoración de la conducta personal como la medición del rendimiento o los resultados obtenidos. Una vez reconocidos sus fines en los mismos términos en que lo hace el preámbulo de la norma y enunciados los criterios a partir de los cuales debe desarrollarse el procedimiento (similares a los marcados por elTREBEP), advierte de la necesidad de que los mismos se desarrollen sin lesionar los derechos de los trabajadores(36). A renglón seguido, establece la necesidad de desarrollo reglamentario de este artículo en relación a la determinación del sistema y el procedimiento y la composición y funcionamiento del órgano encargado de llevarla a cabo, así como en relación los efectos que puede comportar. $Y$ en este punto, cabe destacar que la Comunidad Valenciana ha sido una de las primeras en desarrollar reglamentariamente la evaluación de los funcionarios, como después examinaremos. Por último, se apunta en este artículo 121 como posible consecuencia negativa de la evaluación la remoción del puesto de trabajo obtenido por concurso por el funcionario de carrera, dándose audiencia en todo caso al interesado y a partir de una resolución motivada.

El artículo 3. 5 empieza por declarar que el artículo 121 de la norma valenciana, relativo a la evaluación del desempeño, es aplicable al personal

(35) El Preámbulo resalta, además, que la evaluación, además de concebirse como un elemento clave en relación a la carrera profesional, es una «pieza capital de toda la arquitectura organizativa y en un cambio en la cultura de gestión de personal", por sus implicaciones en aspectos tan variados como las retribuciones, la formación o la provisión de puestos de trabajo. Reconoce, además, que a través de la norma se ha perseguido la consecución de un cambio de cultura en la organización administrativa, que debería girar en torno a la consecución de resultados una vez abandonado el «presencialismo" (Considerando IX).

Véase en relación a la misma MANZANA LAGUARDA, R. S.: La nueva función pública. Una injustificable demora, Tirant lo Blanch, Valencia, 2013, pp. 229 y ss.

(36) Ibídem, pp. 278 y ss. 
docente y estatutario de igual manera que al resto de empleados públicos de la Generalitat, con independencia de su normativa específica. El artículo 66. c), por su parte, contempla como derecho de todos los empleados públicos, sin excepción, el derecho a la implantación de sistemas de evaluación del desempeño objetivos y transparentes (mención que refuerza las obligaciones de información pasiva y activa que la Administración tiene durante el procedimiento). Como contrapartida, en el artículo 94 establece un deber de formación de los mismos a resultas de la obtención de un resultado negativo en el procedimiento de evaluación del desempeño.

El artículo 100. 2. f) identifica como uno de los méritos que podrán valorarse en el concurso en los términos reglamentariamente dispuestos el "resultado de la evaluación del desempeño en destinos anteriores». En sintonía con dicha previsión, el artículo 103. 2 establece la falta de una evaluación positiva como posible causa para la remoción del puesto de trabajo del personal funcionario de carrera titular de un puesto obtenido por dicho sistema de provisión.

Como en el caso de otras normas autonómicas, la prolongación en el servicio activo también aparece vinculada a los buenos resultados en la evaluación del desempeño también en la Comunidad Valenciana. En dicho sentido, el artículo 63. 5. a) identifica como uno de los extremos a tener en cuenta para la aceptación o denegación de la prolongación por parte de la Administración el «Informe emitido por el órgano que ostente la jefatura superior de personal en la Consellería u organismo en el que preste servicios la persona funcionaria que solicite prolongar la permanencia en el servicio activo, en el que se valore su implicación en los objetivos fijados por la organización, el rendimiento o los resultados obtenidos (...)".

Dentro de los efectos que puede tener una evaluación positiva sobre la relación de servicio, se contempla expresamente en la norma la vinculación de la misma a la obtención de retribuciones complementarias, que en principio solo se reconocen al personal funcionario. Como indica el artículo 121. 3, dentro de las mismas es el complemento de actividad profesional el que gratifica una evaluación del desempeño positiva, describiéndose este en el artículo 76 de la norma como aquel "que retribuye el grado de interés, iniciativa o esfuerzo con que el personal funcionario desempeña su trabajo y el rendimiento o resultados obtenidos».

En relación al mismo, la norma además aclara que no tiene un carácter fijo (como es evidente) pero tampoco periódico, y que exige -como no puede ser de otra forma - la planificación de los objetivos a alcanzar y la posterior evaluación de resultados. Además, determina que es necesaria su consignación presupuestaria en el correspondiente programa y la determinación de su cuantía individual por parte de la persona res- 
ponsable del centro directivo en que preste sus servicios el funcionario. Este será el encargado de evaluar el "grado de interés, iniciativa, esfuerzo y compromiso profesional con la organización» en la consecución de los objetivos (37).

En el ámbito de la función pública valenciana pueden ser objeto de negociación colectiva "las normas que fijen los criterios y mecanismos generales en materia de evaluación del desempeño" (154. 2 c). Además, se establece la obligación de remitir a las juntas de personal información acerca de los programas de mejora del rendimiento (artículo 151. a).

Como adelantábamos antes, la Comunidad Valenciana es una de las pocas que ha abordado un profundo desarrollo reglamentario de la evaluación del desempeño. Este se lleva a cabo fundamentalmente a través del Decreto 186/2014, de 7 de noviembre, por el que se regula el sistema de carrera profesional horizontal y la evaluación del desempeño, del personal funcionario de carrera de la Administración de la Generalitat y de la Orden 2/2015, de 3 de diciembre, por la que se desarrolla el sistema de evaluación del desempeño, así como el acceso y el procedimiento de progresión dentro del sistema de carrera profesional horizontal del personal empleado público de carácter fijo de la Administración de la Generalitat. (38)

El primero regula la evaluación del desempeño en relación a la progresión del funcionario en su carrera horizontal, sin hacer referencia ni al personal laboral al servicio de la Administración, ni a la regulación de la misma en relación a la formación, al complemento de actividad profesional o la provisión de los puestos de trabajo (39). El Decreto hace menciones vagas y aisladas a los procedimientos en relación a cada uno de los ámbitos a valorar de forma concreta, limitándose fundamentalmente a

(37) El artículo 76. C) establece además que «En la administración de la Generalitat, la aplicación del complemento de actividad profesional se efectuará de acuerdo con los criterios establecidos por el CIR de conformidad con lo previsto en el artículo 10.4.a. La percepción de este complemento deberá ser autorizada, previamente, por el Consell u órgano competente de la administración pública correspondiente."

(38) Y ello resulta fundamental de cara a asegurar que se concretan los márgenes de discrecionalidad en la actuación de la Administración durante el desarrollo del procedimiento de evaluación. Así lo deja de manifiesto la STS Madrid 968/2012 de 21 de diciembre, que deniega la posibilidad de aplicar por analogía los criterios legislativamente desarrollados para la evaluación de Asesores Técnicos y funcionarios docentes destinados en el exterior y no a quienes ejercen funciones directivas en este ámbito.

(39) La STSJ Valencia 803/2015 de 21 de diciembre de 2015, ha reconocido expresamente el derecho de los funcionarios interinos a recibir el complemento de carrera profesional, al constituir una discriminación no basada en razones objetivas que se les excluyera de esta posibilidad, contraviniendo el principio de igualdad y lo establecido por la cláusula $4 .^{a}$ de Directiva 1999/70/CE del Consejo de 28 de junio de 1999 relativa al Acuerdo marco de la CES, la UNICE y el CEEP sobre el trabajo de duración determinada. En el mismo sentido la STS Valencia 14/2016 de 15 de enero reconoció a los interinos el derecho a la percepción de complementos retributivos por formación permanente cuando procedan a condiciones objetivas de trabajo. 
definir el contenido de los mismos. El artículo 19.1 se refiere a los ámbitos de cumplimiento de objetivos, profesionalidad en el ejercicio de las tareas asignadas, e iniciativa y contribución en la mejora de la prestación del servicio público. Pero además, el texto menciona otros ámbitos a valorar como desarrollo de conocimientos y transferencia de conocimientos. Todos se valoran en relación a todos los grupos de funcionarios, si bien no de la misma manera.

En relación al cumplimiento de objetivos, los artículos 21 y siguientes diferencian entre objetivos colectivos e individuales, si bien el cumplimiento de los segundos está directamente vinculado a la consecución de los primeros. La determinación de la consecución de los objetivos colectivos se lleva a cabo a partir del examen de la actividad que ha venido siendo desarrollada por el Equipo de Gestión de Proyectos o EGP(40). La agrupación de funcionarios en los EGP se determina por el órgano competente en materia de personal de cada Conselleria u organismo equivalente, pudiendo un funcionario pertenecer a varios EGP.

El Reglamento valenciano distingue entre objetivos colectivos de mejora en el servicio público y objetivos colectivos específicos de los EGP. Los objetivos colectivos se plasman en el denominado documento de compromiso de objetivos (o DOCO), que se suscribe anualmente por los responsables de los EGP y cuyo contenido debe ser comunicado a todos sus integrantes.

Por su parte, el documento de compromiso de objetivos individuales (DOCI) es firmado - "cuando se considere conveniente», advierte la norma - por el responsable del Equipo y el funcionario al que se le imponen individualmente (artículo 25. 2). Los modelos normalizados en relación a ambos documentos son aprobados por la Consellería competente en materia de función pública. Resulta muy criticable que se incorpore la mención al DOCl a la que hacemos referencia, por fomentar la inseguridad jurídica y poder dar lugar a una grave lesión de los derechos del trabajador en la medida en que se debilita la base en relación a la cual formular posibles reclamaciones sobre una evaluación negativa. La evaluación es llevada a cabo, en relación a los objetivos colectivos, por parte del "órgano competente», a partir de lo determinado por el responsable del EGP en el informe final de resultados en el que hará constar el grado de cumplimiento de los objetivos. En relación a los objetivos individuales la evaluación se realiza por parte del responsable del EGP, a partir de un cuestionario normalizado también aprobado por la Consellería.

(40) Agrupación de funcionarios, con independencia de su adscripción que tengan encomendada "la realización de un conjunto de tareas coordinadas e interrelacionadas para el cumplimiento de un objetivo específico" 
El segundo de los ámbitos que mide el procedimiento de evaluación del desempeño valenciano previsto en el decreto es el de la profesionalidad en el ejercicio de las tareas asignadas. El artículo 27 identifica la profesionalidad con la "competencia con el que el personal funcionario de carrera (...) desarrolla las actividades que contribuyen a producir los servicios que son el núcleo de la gestión de la organización". La misma se establece en relación a tres parámetros: capacidades, conocimientos y habilidades en el desempeño de las tareas del puesto de trabajo, que deberán evaluarse a través de un cuestionario normalizado rellenado por los titulares de las unidades correspondientes (que a su vez serán valorados por su superior jerárquico o comités de evaluación «en aquellos ámbitos que se determinen»). Se refiere el Decreto además, en este punto, a la introducción de un factor de corrección vinculado al absentismo injustificado durante el periodo evaluado.

El tercero de los ámbitos evaluados es la «iniciativa y participación para la mejora de la calidad del servicio público». El Decreto "premia» en relación al mismo la participación voluntaria en programas de calidad, grupos de expertos, equipos de trabajo para la modernización y otras actividades que se entienda redundan en la calidad del servicio (41).

Respecto a la formación, se describe en función de los objetivos que pretende conseguir (el mantenimiento y la mejora de la competencia profesional, con el fin de contribuir a mejorar el servicio, el desarrollo profesional del empleado y la consecución de los objetivos estratégicos de la Administración). Se reconoce expresamente que la competencia para coordinar su establecimiento, organización y desarrollo le corresponde al Instituto Valenciano de Administración Pública. A efectos de la evaluación se determina que solo se valorarán los impartidos u homologados por el IVAP, los cursos o másteres universitarios en la medida en que guarden relación con la acción de la Administración y los organizados por sindicatos y otras organizaciones promotoras en base a los acuerdos de formación firmados.

En relación al último área, se conceptúa la innovación y transferencia de conocimientos como «el conjunto de actividades realizadas por el personal físico y dirigidas a la difusión del conocimiento técnico y organizativo y la investigación, divulgación y desarrollo en relación a los distintos ámbitos de la Administración». El artículo 32 identifica como transferencia de conocimiento tres aspectos: la docencia presencial u online dirigida a empleados públicos en el marco de acciones formativas llevadas a

(41) A su vez, también se valora la participación en el programa "tutorització del valencià», previsto por el Plan de Fomento del Conocimiento y del uso del valenciano y a través del cual se pretende que los funcionarios con conocimientos oficiales de valenciano los transmitan a la persona tutorizada. 
cabo por escuelas o institutos de formación de personal, la tutoría individual o grupal en relación al personal de la Administración y la coordinación o participación en grupos de trabajo "para la elaboración y puesta en práctica de un proyecto profesional sobre una temática de interés para la Administración".

La investigación e innovación, siempre en relación a la actividad profesional e institucional, hace referencia a la dirección o realización de trabajos de investigación, innovación o calidad. La difusión del conocimiento, por su parte, se refiere a la participación en congresos, jornadas y conferencias y a las publicaciones digitales y en papel, todas ellas relacionadas con la actividad profesional e institucional. Desarrollo de conocimientos y transferencia de conocimientos conforman un único área o dos áreas en función de que sean evaluadas a los funcionarios de los grupos $\mathrm{C} 1$ y $\mathrm{C} 2$ y agrupaciones profesionales funcionariales o a funcionarios de los grupos A1, A2 o B.

El primero de los elementos a destacar de la Orden $2 / 2015$, de 3 de diciembre, por la que se desarrollan tanto el sistema de evaluación del desempeño, como el acceso y el procedimiento de progresión dentro del sistema de carrera profesional horizontal del personal empleado público de carácter fijo de la Administración de la Generalitat, es que es de aplicación también al personal laboral fijo (artículo 2). Ello sin perjuicio de lo que les resulte de aplicación en base al convenio colectivo suscrito.

La norma reglamentaria establece la obligación de incorporar al expediente los méritos obtenidos en relación a la evaluación de cada una de las áreas. Respecto al cumplimiento de objetivos y la profesionalidad, estos méritos se incorporan de oficio. En relación a la iniciativa y contribución, desarrollo de conocimientos y transferencias, será necesario su evaluación y la comprobación de que cumplen los requisitos para ser evaluados por parte de la dirección general competente.

La Orden establece implícitamente la existencia de una aplicación informática a la que se incorporan los distintos méritos a tener en cuenta para el procedimiento de evaluación del desempeño. La aplicación facilita una consulta permanente al expediente por parte del empleado, así como la petición de subsanación de cualquier error detectado. La norma reglamentaria concreta, además, las puntuaciones que los empleados pueden obtener en relación a cada mérito y la calificación mínima exigida en relación a cada una de las áreas evaluadas para acceder a un grado de desarrollo profesional superior en desarrollo de la carrera horizontal.

Puede concluirse por lo aquí expuesto que la valenciana es una de las legislaciones autonómicas más completas en materia de evaluación del desempeño. Sin embargo, entendemos que en ella pueden introducirse mejoras tendentes a limitar la incertidumbre e incrementar la transparencia en el proceso. 
Por su parte, el Anteproyecto de Ley de Empleo Público de la Comunidad Valenciana incorpora relevantes novedades en materia de evaluación del personal. Sin lugar a dudas la más relevante de estas novedades es la creación de la Oficina de Supervisión, Control Interno y Evaluación del Personal de la Administración de la Generalitat, encargada de llevar a cabo la supervisión y el control interno del cumplimiento de las normas sobre función pública y de los deberes profesionales de los empleados públicos, competencias que no dejan de estar atribuidas, no obstante, a la Consellería competente en materia de función pública (artículo 12). Para la realización de estas funciones, la Oficina se crea como un órgano formado por funcionarios de carrera, con la cualidad de autoridad pública y con autonomía e independencia respecto a los órganos a controlar. Para la realización de dichas funciones, la Oficina tiene reconocida la capacidad de requerir cuanta información, datos, estadísticas, documentos y expedientes consideren necesarios a las distintas unidades, órganos, organismos vinculados o dependientes de las Consellerías y consorcios adscritos a la Generalitat.

Entre las funciones expresamente atribuidas a la Oficina, que no obstante requerirán desarrollo reglamentario (artículo 12. 5) están, tanto el análisis de la estructura organizativa de las unidades administrativas y la Administración y la formulación de propuestas de reforma y mejora, informando sobre las actuaciones que proyecten realizar en materia de planificación y reorganización (12. 3. a), como la evaluación del desempeño de los empleados públicos «para optimizar la utilización de los recursos humanos y proponer, en su caso, medidas de reasignación de efectivos." No obstante, solo se contempla que desempeñen tales funciones cuando así les sea expresamente encomendado. La Oficina, además, tiene obligaciones de información, al tener el deber de remitir una memoria de actividades al titular de la Consellería competente en materia de función pública, para su elevación por el Consell. Esta, junto con la información general que pudiera resultar procedente, debe publicarse en la página electrónica de la Generalitat (12. 6).

Resulta criticable que en la norma con rango de Ley no se establezcan los mecanismos que garantizan la independencia del personal que forma parte de la Oficina, ni se establezca como una competencia propia de este órgano, supuestamente independiente, la de desarrollar los procesos de evaluación sin una encomienda expresa. De esta manera nos encontramos con un órgano instrumental, al servicio de la Consellería competente, que más allá de impulsar la evaluación del desempeño - exclusivamente en la Administración autonómica-, no tiene un carácter verdaderamente autónomo garantizado por la Ley. A renglón seguido el Anteproyecto crea, en su artículo 13, la Escola Valenciana 
d'Administració Pública (EVAP), sucesora del sucesora del Institut Valencià d'Administració Pública, como centro encargado de planificar, coordinar y gestionar las políticas relacionadas con la formación y aprendizaje profesional del personal empleado público de las Administraciones valencianas.

Además, el Anteproyecto valenciano incorpora una nueva regulación de la evaluación del desempeño, si bien no supone importantes novedades. En base a un recorrido ordenado por su articulado, debemos de poner de relieve en primer término que atribuye la competencia en materia de diseño y organización de los procesos de evaluación a la Consellería competente en materia de función pública (artículo 9. 1. h). En segundo lugar amplia a los Directivos públicos el régimen de evaluación del desempeño previsto en la Ley (artículo 19. 7).

El Anteproyecto establece como requisito necesario para la prolongación de la permanencia en el servicio activo - siempre y cuando el solicitante disponga de cotizaciones suficiente para causar derecho a la pensión íntegra de jubilación-, entre otros un informe emitido por el Órgano que ostente la jefatura superior de personal en la Consellería u Organismo en el que trabajador preste sus servicios. En dicho informe, además de otras cuestiones, debe valorarse la implicación del trabajador en los objetivos fijados por la organización, el rendimiento, los resultados obtenidos y los resultados negativos en la evaluación del desempeño durante los tres años anteriores a la solicitud (artículo 72. 5. b. 1).

El artículo 75. 1. c) contempla entre los derechos del funcionario el que tiene a la implantación de sistemas de evaluación del desempeño objetivos y transparentes. Por su parte, el artículo 96. 2 establece expresamente que el cumplimiento del Código de Conducta por parte de los empleados puede ser tenido en cuenta en la evaluación del desempeño. Cabe destacar, además, que el artículo 105 consagra un deber genérico de formación, entre otros supuestos, cuando se detecte una necesidad formativa como consecuencia de los procedimientos de evaluación del desempeño.

El artículo 109. 2. a) reconoce los resultados de la evaluación del desempeño como un posible mérito a valorar en el concurso. Resulta destacable que los resultados de la evaluación del desempeño son considerados mérito preferente, debiendo tenerse en cuenta en caso de empate. Por su parte, el artículo 114 en conexión con el artículo 135. 5 , reconoce como causa de remoción del personal funcionario de carrera titular de un puesto de trabajo obtenido por concurso, la evaluación negativa del desempeño mediante resolución del órgano que realizó el nombramiento, oída la junta de personal y previo expediente contradictorio. 
El artículo 135 está íntegramente consagrado a la evaluación del desempeño, estableciendo unos principios de carácter genérico a tener en cuenta en el procedimiento. Como ya sabemos, dicha evaluación cuenta con un profundo desarrollo reglamentario en la Comunidad. Así, en primer término, el artículo define la evaluación como «el procedimiento mediante el cual se mide y valora la conducta profesional y el rendimiento o el logro de resultados". Resulta bastante significativa la forma de concluir dicha definición, pues el Anteproyecto valenciano concreta que la finalidad de la misma es la individualización y diferenciación de la contribución de los empleados públicos. De esta manera, se pone de relieve la elección de un modelo de evaluación que pretende el reconocimiento en distintos ámbitos de la singularidad del trabajador, tanto en relación a su conducta como en relación a la consecución de objetivos o resultados.

El artículo establece la necesidad de que todas las administraciones públicas incluidas en el ámbito de aplicación del Anteproyecto (Administración autonómica, consorcios, Administración local y Universidades públicas) implanten sistemas de evaluación. Estos deben orientarse a la mejor gestión de las administraciones, al progreso y desarrollo profesional de los empleados públicos y al favorecimiento de su motivación, implicándoles en los objetivos previamente fijados por la organización en virtud de lo reglamentariamente establecido (artículo 135. 2).

Como principios del procedimiento (inherentes a los instrumentos que conformen los sistemas de evaluación) se consagran los de transparencia, publicidad, objetividad, fiabilidad y relevancia de contenidos, imparcialidad y no discriminación y respeto a los derechos de los empleados públicos. Procedimiento, periodicidad, composición y funcionamiento de los órganos que la llevan a cabo, efectos de su resultado sobre carrera horizontal, formación, provisión de puestos de trabajo y percepción de complemento de actividad profesional se reconocen como materias de desarrollo reglamentario en las que la Ley no profundiza.

\section{II.7. Extremadura}

El Título VII de la Ley 13/2015, de 8 de abril, de Función Pública de Extremadura, (LFPEX), es el encargado de regular la promoción profesional y la evaluación del desempeño, conceptos que aparecen ligados en la norma extremeña. El epígrafe IX de su Exposición de motivos ya nos adelanta que la evaluación del desempeño se vincula a la carrera horizontal y que es obligatoria en todas las Administraciones extremeñas. Más allá de que algunos de sus aspectos más relevantes se dejen a desarrollo regla- 
mentario, la LFPEX incorpora importantes previsiones en relación a la misma. El artículo 2. h) identifica como uno de los principios y fundamentos de actuación que ordenan la función pública extremeña los de evaluación del desempeño y responsabilidad en la gestión, ligando ambos conceptos. En los preceptos siguientes aborda el ámbito competencial en relación al procedimiento objeto de nuestro estudio, atribuyéndole al Consejo de Gobierno las funciones de impulsar la unificación de criterios en la materia y promover la cooperación administrativa con las entidades locales en la materia. Además, la Consejería competente en materia de función pública tiene atribuida la función de realizar propuestas encaminadas a la continua mejora del sistema.

Los artículos 105 y 113 al abordar la evaluación del desempeño lo hacen ligándola a la carrera horizontal, constituyéndose la primera en uno de los elementos a valorar para determinar la progresión en la segunda. Sin embargo, acertadamente, la norma extremeña no reconoce expresamente tan solo la ligazón entre dicha modalidad de carrera y la evaluación del desempeño sino que, a diferencia de la práctica totalidad de normas en materia de función pública, menciona expresamente la necesaria vinculación de la evaluación del desempeño con cualquiera de las modalidades de carrera reconocidas en la Ley como propias de la función pública extremeña que se implante en la correspondiente administración (artículo 113.7) (42). La LFPEX no describe el procedimiento de evaluación, remitiéndose a un posterior desarrollo reglamentario (artículo 113. 5), pero si lleva a cabo una regulación básica de algunos aspectos fundamentales de la evaluación.

El artículo 113, además de establecer la obligatoriedad de que las administraciones extremeñas establezcan procedimientos de evaluación del desempeño, lo define como el «instrumento que posibilita la evaluación y valoración de la conducta profesional y el rendimiento o el logro de resultados de cada empleado público.» El mismo, además, alude a la necesidad de llevar a cabo un procedimiento de descripción y análisis de los puestos previo a la implantación de la evaluación del desempeño. A diferencia de lo que ocurre en otras legislaciones autonómicas e incluso en la legislación estatal, el deber establecido por la norma extremeña no es un deber genérico (43). En su segundo epígrafe se reproducen como criterios rectores los que ya cita el TREBEP y en el tercero se establecen como ob-

(42) Sobre la posible vinculación de la evaluación del desempeño con la carrera vertical, véase ARROYO LLANES, L. M.: "La carrera profesional y la evaluación del desempeño de los funcionarios públicos", Revista Catalana de Dret Public 45, 2012., pp. 118 y ss.

(43) La disposición transitoria primera concreta que esa obligación de las Administraciones extremeñas de implantar sistemas de evaluación del desempeño debe materializarse en un plazo máximo de cuatro años a partir de la entrada en vigor de la misma (a partir, por tanto, del 8 de abril de 2016). 
jetivos de los sistemas de evaluación la mejora del rendimiento, la motivación y la formación. La norma extremeña establece la obligación de utilizar los datos derivados de las evaluaciones en la revisión de puestos y en el diseño y revisión de los procesos de formación y selección.

La LFPEX identifica en su artículo 57. 2. a) las retribuciones complementarias de puesto de trabajo, que reconoce expresamente a todos los funcionarios, con independencia de que sean fijos o interinos e incluso al personal eventual (artículo 63. 2), pero no al personal laboral, al menos no sin que lo reconozca expresamente y de forma previa el pertinente convenio colectivo. Entre las mismas se citan el componente específico del complemento de puesto de trabajo, el complemento de carrera profesional o el complemento variable vinculado a objetivos, que pueden vincularse de una u otra manera a la carrera horizontal. La LFPEX establece que «las normas que fijen los criterios y mecanismos generales en materia de evaluación del desempeño" son objeto de negociación colectiva (artículo 79). También la evaluación del desempeño positiva se reconoce expresamente como mérito valorable en los concursos para la provisión de puestos de trabajo (artículo 117.1. e).

La norma extremeña configura la formación como un derecho y como un deber, asociando ambas vertientes a la mejora del desempeño (artículos 70 y 71). La asistencia a actividades formativas - siempre vinculadas a las tareas que le sean propias al empleado público- es obligatoria y únicamente está justificado no asistir a las mismas en base a causa justificada. Vinculada a la obtención de una evaluación negativa se contempla también la posibilidad de denegar la prolongación de la permanencia en el servicio activo (artículo 85. 4. a) o la de, motivadamente y previa audiencia del interesado, abandonar un puesto de trabajo obtenido por concurso (artículos 113. 6 y 120). Se reconoce además la posibilidad expresa de que la evaluación del desempeño sea uno de los criterios a tener en cuenta en un proceso de reasignación de efectivos (artículo 127) y se configura la falta injustificada de rendimiento como una posible falta grave (artículo 153. g).

\section{II.8. Galicia}

La norma gallega es, junto con la castellano-manchega o la valenciana una de las leyes autonómicas en materia de función pública que con mayor detalle aborda el objeto de nuestro estudio (44). Ya el epígrafe VII de

(44) Véase sobre la evaluación del desempeño en la norma autonómica gallega sobre función pública MÍGUEZ MACHO, L.: "La carrera administrativa: la provisión de puestos de trabajo y la promoción profesional. La evaluación del desempeño de los empleados públicos» en MARTíNEZ-CAMPOS, S. y FERNÁNDEZ FARRERES, G. J.: El empleo público en tiempo de reformas, Marcial Pons, Madrid, 2014, pp. 85 a 111. 
su Exposición de motivos liga la figura a la de la carrera horizontal, aunque la evaluación del desempeño también afecta a otros ámbitos de la relación de servicio. Pese a aludir expresamente al desarrollo reglamentario de la figura, la Ley 2/2015, de 29 de abril, del empleo público de Galicia, (LEPGAL), establece una serie de principios básicos comunes, fundamentalmente en lo referido a su configuración como procedimiento individualizado en relación a cada empleado y no global de las unidades administrativas (como se contempla en la legislación de otras Comunidades Autónomas, señaladamente en el desarrollo reglamentario de la norma asturiana), que se lleva a cabo en base a criterios y procedimientos de carácter colectivo.

La sección 2. a del Capítulo II se encuentra íntegramente consagrada a la evaluación del desempeño, que se define en la norma gallega en los mismos términos que en el TREBEP. Se reconocen los mismos criterios inspiradores y se establece la obligación de implantación de sistemas de evaluación del desempeño en todas las Administraciones gallegas. Si bien no se determina un plazo concreto para el establecimiento efectivo de estos sistemas, si que se prevé expresamente la obligación, por parte de la Dirección General competente en materia de Administración local de la Xunta, de colaborar con las Entidades Locales en la implantación de sistemas de evaluación del desempeño.

Con el fin de garantizar la efectiva defensa de los derechos de los empleados públicos, el artículo 83 incorpora dos referencias destacables: la primera que en el diseño y establecimiento de los sistemas de evaluación han de ser oídas las organizaciones sindicales. No obstante, el artículo 157. 1. a) reconoce expresamente la competencia de juntas y delegados de personal para recibir información acerca de los programas de rendimiento a implementar en las distintas unidades administrativas. La segunda, que los sistemas se aplican por órganos especializados dotados de autonomía funcional.

El régimen jurídico de la evaluación del desempeño configurado por la norma gallega determina necesariamente dos criterios a tener en cuenta y se calcula en relación a la consecución de dos fines. Son criterios necesariamente a tener en cuenta para llevar a cabo la evaluación, tanto el grado de cumplimiento de los deberes profesionales impuestos por la Ley a los empleados, como "el grado de interés, iniciativa y esfuerzo con el que los empleados realizan su trabajo y, en particular la implicación de los mismos en la actualización y perfeccionamiento de su cualificación profesional». Son fines en relación a cuya consecución se realiza la evaluación -siempre individual- del empleado, tanto la consecución de los objetivos de la unidad administrativa como «la mejora en la organización y gestión administrativas mediante la participación en procesos de inno- 
vación y buenas prácticas en favor de la excelencia y la normalización y racionalización de procesos».

El artículo 85 establece el carácter periódico de la evaluación (sin entrar en mayores detalles), determinándose como consecuencia de una evaluación negativa, tanto la no percepción del complemento de desempeño como la obligación de formación, además de la posible pérdida del puesto de trabajo obtenido por concurso (artículo 94) (45). Sin embargo, no son estos los únicos efectos aparejados a una evaluación del desempeño negativa recogidos en la norma. El artículo 68. 4. a) determina que puede no concederse la prolongación de la permanencia en la situación de servicio activo a consecuencia de los resultados de la evaluación del desempeño(46). Entre los efectos que puede tener en la relación de servicio una evaluación del desempeño positiva están, lógicamente, los vinculados a la promoción profesional en el ámbito de la carrera horizontal (artículo 77. b) y la obtención del complemento de desempeño al que hace referencia expresa el artículo 137. 2. c), que se reconoce expresamente a todos los funcionarios (incluidos los funcionarios en prácticas), pero no al personal laboral ni tan siquiera al personal directivo. Las normas que fijen criterios y mecanismos generales en materia de evaluación del desempeño son objeto de negociación colectiva como expresamente señala el artículo 153. d).

\section{II.9. País Vasco}

Pese a no definir ni tratar con profundidad el régimen jurídico de la evaluación del desempeño, la Ley 6/1989, de 6 de julio, de la Función Pública Vasca, (LFPVAS) sí hace referencia, como muchas de las legislaciones autonómicas que entraron en vigor con anterioridad al TREBEP, tanto a aspectos competenciales como a una serie de consecuencias sobre la relación de servicio derivadas del sentido de la evaluación practicada al

(45) El artículo 34. 6, por su parte, reconoce expresamente la vinculación directa que existe entre la conservación del puesto de trabajo de directivo profesional y la obtención de evaluaciones de desempeño positivas, como también hace elTREBEP.

(46) Y en relación a la misma, el TSJ Galicia 00409/2016 de 14 de junio de 2016, ha declarado que al anudar la regulación legal "la aceptación o denegación de las solicitudes de prolongación de servicio activo a los «resultados de la evaluación del desempeño de la persona solicitante", sin que imponga el legislador la existencia de motivos o circunstancias tasados ni requisitos específicos. Así la "evaluación negativa" se alza en concepto jurídico indeterminado cuya existencia puede discutirse y debe ser objeto de prueba.». Dicha Sentencia avala una Resolución de 2 de Febrero de 2015 de la Xunta en relación a la denegación de la prolongación en la vida activa de un recurrente, profesor responsable de la expulsión de 136 alumnos durante un solo curso académico. 
empleado público (47). En relación al primero de los aspectos, el artículo 6. 1. b) le atribuye al Departamento de Presidencia, Justicia y desarrollo la competencia para la promoción, coordinación y en su caso ejecución de medidas e iniciativas tendentes a la mejora del rendimiento en el servicio y su promoción.

Respecto a los efectos de una evaluación del desempeño de carácter negativo, la norma vasca cita como causa de remoción de aquellos funcionarios que accedan a un puesto de trabajo mediante el procedimiento de concurso «una falta de capacidad para su desempeño manifestada por rendimiento insuficiente que impida realizar con eficacia las funciones atribuidas al puesto" (50. 3). Esta solo puede tener lugar previo expediente e informe del órgano de representación y mediante resolución motivada del órgano que llevó a cabo el nombramiento.

En cuanto a las consecuencias aparejadas a una evaluación del desempeño de carácter positivo, cabe destacar que en relación al concurso (sistema normal de provisión en el ámbito de la función pública autonómica vasca), se determina como mérito a tener en cuenta "la valoración del desempeño de puestos de trabajo anteriormente ocupados" (artículo 46. 4). También es preciso destacar la referencia al complemento de productividad (artículo 79. 1), que, como retribución complementaria solo se reconoce en la norma vasca expresamente a los empleados con la condición de funcionario y que tiene como objeto la retribución del «especial rendimiento, la actividad extraordinaria y el interés o iniciativa con que el funcionario desempeña su puesto de trabajo.»

Además se lleva a cabo una referencia velada a la evaluación del desempeño al hacer referencia a los deberes y faltas de los funcionarios. Entre los primeros se encuentra el desempeño eficaz de las funciones encomendadas (artículo 73. 1) y entre las segundas la notoria falta de rendimiento, que será muy grave o solamente grave en función de que implique o no inhibición en el cumplimiento del trabajo encomendado (artículos 83. f y 84. j).

Por último, cabe destacar que el artículo 97.3 conceptúa el cumplimiento del perfil lingüístico como exigencia obligatoria para el desempeño del puesto de trabajo (perfil que, dentro de la función pública autonómica, determina "el conjunto de los niveles de competencia

(47) Sobre la necesidad de elaboración de una nueva ley de empleo público para el país vasco y de que esta haga referencia a la profesionalización de la función pública y una cultura de responsabilidad por la gestión, especialmente en momentos de restricciones económicas y necesarias reformas administrativas de cara a asegurar su sostenibilidad, véase JIMÉNEZ ASENSIO, R.: "Una nueva Ley de Empleo Público para Euskadi: inercia versus innovación» Pertsonak eta Antolakunde Publikoak Kudeatzeko Euskal Aldizkaria/Revista Vasca de Gestión de Personas y Organizaciones Públicas 1, 2011, pp. 11 a 34 
lingüística en euskera necesarios para la provisión y desempeño de puestos de trabajo).

El Proyecto de Ley de Empleo Público Vasco introduce definitivamente con carácter general la evaluación del desempeño en el ámbito del empleo público autonómico, incorporándola en el artículo 2. 2. h) como uno de los principios de actuación y gestión del empleo público vasco. El artículo 14 le reserva al Gobierno Vasco el establecimiento del sistema de evaluación de acuerdo a lo establecido en la Ley y la determinación de los efectos de la misma a propuesta del Departamento competente en la materia, al que el artículo 15. 2. f) le confiere el impulso, la dirección la coordinación y la puesta en práctica de la política de análisis y racionalización de puestos de trabajo, así como el establecimiento de criterios para la evaluación en base a la normativa. Por su parte, el artículo 10 crea la Comisión de Coordinación del Empleo Público de Euskadi, adscrita al Departamento competente en materia de empleo público, como órgano de consulta y coordinación en materia de empleo público. Entre sus atribuciones está el impulso a la unificación de criterios en materia de evaluación (artículo 12. f).

Resulta interesante la inclusión expresa del personal interino en los sistemas de evaluación del desempeño que lleva a cabo la norma vasca, en la medida en que el artículo 26.3 . c) reconoce el rendimiento insuficiente derivado de los procedimientos de evaluación como posible causa de cese. Asimismo, el artículo 27. 5 reconoce la sumisión del personal directivo a los procedimientos de evaluación del desempeño.

A la evaluación del desempeño se consagra íntegramente el artículo 54 del Proyecto, determinando la necesidad de que las Administraciones Públicas Vascas establezcan reglamentariamente dichos procedimientos. El Proyecto configura la evaluación como instrumento en los mismos términos que el TREBEP, incorporando como criterios a tener en cuenta en su diseño los de relevancia de los contenidos, fiabilidad de los instrumentos, objetividad de las medidas, transparencia, no discriminación respeto a los derechos del personal empleado público y, para cuyo desarrollo es necesaria la previa descripción de los puestos de trabajo (artículo 54. 4).

El Proyecto indica expresamente la posibilidad de utilización de los datos en la revisión de puestos de trabajo, y en el diseño y revisión de procesos de formación y selección. Como en otros casos vistos a lo largo de páginas precedentes, el Anteproyecto vasco simplemente enumera los ámbitos en los que la evaluación puede tener consecuencias, remitiéndose al reglamento para la determinación de las mismas (carrera profesional, promoción interna, formación, provisión de puestos de trabajo, la continuidad en el puesto y las retribuciones complementarias a las que hacen referencia los artículos 136.2 B) y 136.2 C, 
que requerirán en todo caso la previa regulación y aprobación de los sistemas).

La norma fija otra consecuencia de la evaluación positiva: el ascenso en el grado de desarrollo profesional con independencia $-y$ esta es una incorporación positiva y relevante- del sistema de carrera vigente en cada Administración (artículo 94. 8). Por su parte, una valoración de carácter negativo traerá aparejada tanto la no valoración del mérito de experiencia durante el periodo evaluado en la selección y provisión como - al tener un carácter continuado - la remoción del puesto obtenido por concurso, previa audiencia y en base a una resolución motivada (105. 1. b). Hay que tener en cuenta, además, que el artículo 104. 1. a) establece la necesidad de tener en cuenta el resultado de dicha evaluación en los concursos para la provisión, siempre y cuando esta exista. La evaluación negativa también puede llevar aparejada la revocación de la Comisión de Servicio (artículo 112. e) y se tiene en cuenta para la reasignación de efectivos (artículo 117. 2).

El Proyecto vasco reconoce la evaluación del desempeño negativa - durante los tres años anteriores - como posible causa para la denegación de la prolongación de la permanencia en el servicio activo hasta los setenta años (artículo 68. 4. a). El mismo le otorga la competencia para el diseño, organización y evaluación de programas formativos vinculados a necesidades localizadas a partir de los procesos de evaluación del desempeño.

\section{Conclusiones}

Una década después de la incorporación de la evaluación del desempeño al ordenamiento jurídico estatal, muchas Comunidades Autónomas aún no han introducido la figura en su normativa general sobre función pública. Esa es la razón por la que, a lo largo de este estudio, no hemos hecho referencia a las legislaciones andaluza, catalana, canaria, cántabra, riojana, madrileña o murciana. Ello supone un primer aspecto sobre el que llamar la atención: el incumplimiento del mandato contenido en el artículo 20. 1 TREBEP. Si bien ello no implica que en el ámbito de estas Comunidades la evaluación del desempeño sea inexistente, esta se contempla de forma sectorial y en relación con determinados ámbitos, especialmente el sanitario.

Si la normativa básica en materia de evaluación del desempeño establecida en elTREBEP es escasa y ello es criticable, también lo resulta a su vez que las Comunidades Autónomas, que tienen la capacidad y la obligación de desarrollar dichos preceptos, no lo hagan en su norma general sobre función pública. No olvidemos que la evaluación del desempeño en 
el ámbito del empleo público está o puede llegar a estar ligada a aspectos tan relevantes como las retribuciones, la formación, la continuidad en el puesto obtenido por concurso o el desarrollo de la carrera administrativa.

De las Comunidades que han completado el régimen jurídico básico en materia de evaluación, podemos destacar determinados aspectos que estimamos debería haber previsto el propio TREBEP. En primer lugar se hace preciso poner de manifiesto la necesidad, expresamente prevista, por ejemplo por el artículo 66. 4 LEPCM, de llevar a cabo un análisis y descripción de los puestos de trabajo previo a la puesta en marcha de todo procedimiento de evaluación (48).

Otro aspecto relevante es la necesidad de evitar la excesiva referencia a multitud de conceptos jurídicos indeterminados en la legislación general en materia de evaluación del desempeño. En tal sentido entendemos que los criterios referenciados en el artículo 66. 5 LEPCM resultan insatisfactorios, al ser excesivamente diversos y poco homogéneos para ser de aplicación general (49). Por el contrario, parece más acertada la técnica legislativa empleada en la redacción del artículo 84. 1 LEPGAL. Este determina que el procedimiento de evaluación del desempeño en dicha Comunidad tendrá necesariamente en cuenta como criterios dos factores: «el grado de cumplimiento de los deberes profesionales que esta ley impone a los empleados públicos" y "el grado de interés, iniciativa y esfuerzo con los que los empleados públicos realicen su trabajo y, en particular, la implicación de los mismos en la actualización y perfeccionamiento de su cualificación profesional». Esta opción contrasta con la elegida por otras legislaciones, como la castellano y leonesa, que, pese a referirse también a dos criterios se ciñe a aspectos que únicamente ponen en valor la capacidad organizativa de las unidades (50).

\footnotetext{
(48) Véase, sobre la relevante autonomía en relación a la ordenación de puestos de trabajo existente en las Administraciones españolas ARROYO LLANES, L. M.: "La evaluación del desempeño en la función pública: ámbito de operatividad y contexto administrativo» en FUENTETAJA PASTOR, J. A. y CANTERO MARTÍNEZ, J. (Dirs.): Crisis económica y función pública, Aranzadi, Cizur Menor, 2012, pp. 224 y ss.
}

(49) En el mismo sentido GORRITI BONTIGUI, M. en "La evaluación de desempeño en la Ley de Empleo Público de Castilla-La Mancha», Revista jurídica de Castilla-La Mancha, 50, 2011, p. 350, que acertadamente señala además que "esto puede ser contradictorio cuando se establece que es el análisis de puestos el que determinará los contenidos de la medida. Además, puede ser un corsé que limite la especificidad de la medida de puestos de diferente naturaleza»

(50) Concretamente, el artículo 70. 2 LFPCyL hace referencia a "la organización de la unidad sometida a evaluación, o de las unidades sobre las que despliega sus efectos el puesto directivo en el caso de ser éste el sometido a evaluación, y el resultado obtenido en relación con los medios personales y materiales de que se dispone así como en relación con los objetivos propuestos" y a "la capacidad organizativa así como las propuestas y mejoras introducidas en la unidad y en su funcionamiento a instancia de su titular. En el supuesto de evaluación de puestos directivos, la capacidad de dirección, organización y mejora de las diferentes unidades y funciones comprendidas en su ámbito de actuación introducidas a instancia del titular del puesto directivo.» 
En cuanto a los mecanismos de recurso, se hace precisa una referencia expresa a los mismos, y que las distintas legislaciones prevean la creación de órganos independientes llamados a resolverlos. Se trataría de entes como la Oficina de Supervisión, Control Interno y Evaluación del Personal de la Administración de la Generalitat, prevista por el Proyecto de Ley valenciano o la Comisión de Coordinación del Empleo Público de Euskadi prevista por el Proyecto de Ley Vasco, que no cuenta con estas funciones expresamente atribuidas. En relación a la misma y a otros órganos de similar naturaleza, debería asegurarse legalmente su independencia y la autonomía en relación al ejercicio este tipo de funciones.

Las Comunidades Autónomas tienen la obligación de diseñar procedimientos de evaluación integrales, que no generen desigualdades intolerables entre los distintos empleados públicos. Sin embargo, determinadas legislaciones autonómicas únicamente contemplan la evaluación del desempeño para determinados empleados públicos, como en el caso de Castilla y León, que la reserva expresamente a puestos directivos y unidades con rango igual o superior a la jefatura de servicio que integran la Administración autonómica (51)

No obstante, otras legislaciones autonómicas hablan expresamente de la extensión de los procedimientos de evaluación del desempeño a todos los empleados públicos, con independencia de su tipología, si bien no lo hacen todas con la misma claridad. Entre las menos transparentes podemos citar el caso del artículo 66 de la norma castellanomanchega, que resulta contradictorio en sus dos primeros epígrafes al establecer la generalización en relación a su personal de los sistemas de evaluación del desempeño para describirlo en el segundo de sus epígrafes como un procedimiento aplicable exclusivamente a los funcionarios, o el artículo 113 LFPEX (aunque en este supuesto cabrían interpretaciones, dada la ligazón que el mismo artículo establece entre la evaluación del desempeño y la carrera profesional, derecho que se reconoce exclusivamente al funcionario de carrera, como indican tanto

\footnotetext{
(51) En este sentido, debemos recordar el contenido del FJ IV de la STS de 3 de marzo de 2006 que, al abordar la posible nulidad de las retribuciones variables por objetivos a las que hacía referencia el Decreto 2/2003, aprobado por Acuerdo del CGPJ de 3 Diciembre de 2003 relativo al régimen retributivo de las carreras judicial y fiscal puso de manifiesto que "el otorgamiento de una auténtica tutela judicial efectiva, exige a jueces y magistrados la intervención, examen y resolución perfectamente individualizada y motivada en relación con el concreto y particular asunto objeto de controversia, y ese estudio pormenorizado ha de traducirse necesariamente en criterios de calidad y atención individualizada, incompatibles en ocasiones con únicas referencias cuantitativas en cuanto a número de asuntos resueltos, según parámetros que resulten puramente productivistas, y por tanto ajenos o alejados de un estudio ponderado y reflexivo."

El alcance por parte de jueces y magistrados de los objetivos de rendimiento impuestos para alcanzar determinados incrementos retributivos ha sido profusamente tratado por la jurisprudencia del Tribunal Supremo a través de Sentencias como las de 23 de junio de 2011, en base a los recursos $549 / 2010,550 / 2010,558 / 2010$ o 560/2010.
} 
el artículo 16 TREBEP como el propio artículo 102 de la norma extremeña). Algo muy similar ocurre, tras una lectura del conjunto del texto autonómico consagrado a la función pública, en relación con el artículo 39 LFPIBAL.

Esta evidente lesión al artículo 14 de la Constitución Española contraría, además, lo expresamente establecido por la cláusula $4 .^{a}$ de Directiva 1999/70/CE del Consejo de 28 de junio de 1999 relativa al Acuerdo marco de la CES, la UNICE y el CEEP sobre el trabajo de duración determinada (52). La misma es de aplicación directa en España desde que el 10 de julio de 2002 transcurrió su plazo de transposición al ordenamiento jurídico estatal. Recordando la necesidad de que la diferencia de trato entre los trabajadores no se justifique en función de la temporalidad en el seno de la Administración, se pronunciaron las STJUE de 13 de septiembre de 2007 (Del Cerro Alonso contra Servicio Vasco de Salud, asunto c-307/05), que en su epígrafe 26 establece que el propósito de la Directiva es "no sólo establecer un marco para evitar los abusos derivados de la utilización de sucesivos contratos o relaciones laborales de duración determinada, sino también mejorar la calidad del trabajo de duración determinada garantizando el respecto del principio de no discriminación.» (53)

Más adelante y en relación con el Reglamento autonómico en materia evaluación del desempeño se ha llegado a una solución similar por parte de los tribunales españoles. Así, la sentencia 803/2015 de 21 de diciembre del TSJ de Valencia en relación con el recurso 66/2015, interpuesto por la Asociación de Interinos de la Generalitat Valenciana contra el Decreto $186 / 2014$, en la medida en que excluía a los interinos con más de cinco años de antigüedad de la posibilidad de percibir el complemento de carrera

(52) Según la misma:

Principio de no discriminación (cláusula 4)

1. Por lo que respecta a las condiciones de trabajo, no podrá tratarse a los trabajadores con un contrato de duración determinada de una manera menos favorable que a los trabajadores fijos comparables por el mero hecho de tener un contrato de duración determinada, a menos que se justifique un trato diferente por razones objetivas.

2. Cuando resulte adecuado, se aplicará el principio de pro rata temporis

3. Las disposiciones para la aplicación de la presente cláusula las definirán los Estados miembros, previa consulta con los interlocutores sociales, y/o los interlocutores sociales, según la legislación comunitaria y de la legislación, los convenios colectivos y las prácticas nacionales.

4. Los criterios de antigüedad relativos a determinadas condiciones de trabajo serán los mismos para los trabajadores con contrato de duración determinada que para los trabajadores fijos, salvo que criterios de antigüedad diferentes vengan justificados por razones objetivas.

(53) Reafirmando la posibilidad de aplicar este principio de igualdad al seno de la Administración la STJUE de 8 de septiembre de 2011 (Francisco Javier Rosado Santana / Consejería de Justicia y Administración Pública de la Junta de Andalucía, asunto c-177/10). 
profesional. La justificación está en la inexistencia de "razones objetivas» - como la naturaleza de las tareas o el cumplimiento de un objetivo de política social-, que justifiquen un trato desigual a los trabajadores temporales en relación con los indefinidos. En un sentido similar, la STS de 30 de junio de 2014 desestimó un recurso de casación interpuesto por la Comunidad Autónoma de Castilla y León en relación con la Sentencia que anuló la disposición adicional segunda del Decreto Autonómico 43/2009. Esta, rechazaba la posibilidad de que los estatutarios sanitarios interinos de larga duración accedieran al complemento de carrera profesional.

\section{Bibliografía}

ADIEGO SAMPER, C.: «Evaluación del desempeño. Un sistema integral» en VELÁZQUEZ LÓPEZ, F. J. y HERRERA DÍAZ-AGUADO, L. (Coords.): Cooperación en la formación entre instituciones, INAP, Madrid, 2015 pp. 211 a 315.

ARROYO JIMÉNEZ, L.: Libre empresa y títulos habilitantes, Centro de Estudios Políticos y Constitucionales, Madrid, 2004.

ARROYO LLANES, L. M.: "La carrera profesional y la evaluación del desempeño de los funcionarios públicos", Revista Catalana de Dret Public 45, 2012, pp. 94 a 128.

"La evaluación del desempeño en la función pública: ámbito de operatividad y contexto administrativo" en FUENTETAJA PASTOR, J. A. y CANTERO MARTINEZ, J. (Dirs.): Crisis económica y función pública, Aranzadi, Cizur Menor, 2012, pp. 219 a 259.

BACCI, A., BUONAURO, C., CAROSI, A., CLARICH, M., De ANGELIS, L. M., MATTARELLA, B., NADDEO, A., PANOCCHIA, I. y VERBARO, F: II nuevo ordinamento del lavoro pubblico e il ciclo della performance, Promo P. A. Fondazione, Lucca, 2010, pp. 181 a 193.

BASOREDO LEDO, C. y LÓPEZ BASTERRA, J.: «Bases de un modelo de evaluación de méritos profesionales en la administración pública centrado en el desempeño" Pertsonak eta Antolakunde Publikoak Kudeatzeko Euskal Aldizkaria/Revista Vasca de Gestión de Personas y Organizaciones Públicas 5, 2013, pp. 8 a 19.

BELLOWS, R.M. y ESTEP, M. F.: Employment Psychology: The Interview, Rinehart, New York, 1954.

CASTILLO BLANCO, F:: «¿Es precisa una reforma del sistema retributivo de los funcionarios públicos? Una reflexión mirando a la historia.», Revista Española de Derecho Administrativo 112, 2001, pp. 493 a 532.

CONDREY, S. E.: "Public human resource management: how we get where we are today" en RICCUCCI, N. M.: (Dir.) Public personnel management. Current concerns, future challenges, Longman, Boston, 2011, pp. 1 a 13. 
FOMBELLIDA ARAGÓN, R.: "La gestión de personas a través del desempeño de competencias", Auditoría Pública 43, 2007, pp. 39 a 50.

GORRITI BONTIGUI, M: "La evaluación del desempeño: análisis, retos y propuestas. Una aplicación a la Comunidad Autónoma de Aragón", Revista Aragonesa de Administración Pública 13, 2011, pp. 297 a 320 .

"La evaluación de desempeño en la Ley de Empleo Público de CastillaLa Mancha", Revista jurídica de Castilla-La Mancha, 50, 2011.

GRÉGOIRE, R.: La fonction publique, A. Colin, Paris, 1954, pp. 343 a 370.

HUNTER, J.E. y SCHMIDT, F.L.: Methods of meta-analysis: Correcting for error and bias in research findings, Sage, Newbury Park, CA 1990.

JIMÉNEZ ASENSIO, R.: "Una nueva Ley de Empleo Público para Euskadi: inercia versus innovación" Pertsonak eta Antolakunde Publikoak Kudeatzeko Euskal Aldizkaria/Revista Vasca de Gestión de Personas y Organizaciones Públicas 1, 2011, pp. 11 a 34.

MADUREIRA, C.: "Sistema integrado de avaliação de desempenho na administração pública portuguesa (SIADAP). Balanço de uma década", Lusíada. Economia \& Empresa. 20, 2015, pp. 171 a 194.

MANZANA LAGUARDA, R. S.: La nueva función pública. Una injustificable demora, Tirant lo Blanch, Valencia, 2013.

MÍGUEZ MACHO, L.: "La carrera administrativa: la provisión de puestos de trabajo y la promoción profesional. La evaluación del desempeño de los empleados públicos» en MARTíNEZ-CAMPOS, S. y FERNÁNDEZ FARRERES, G. J: El empleo público en tiempo de reformas, Marcial Pons, Madrid, 2014, pp. 85 a 111.

NIETO GONZÁLEZ, A.: "La retribución de los funcionarios en España. Historia y actualidad", Revista de Occidente, Madrid, 1967.

NIGRO, LL. G. y KELLOUGH, J. E.: The new public personnel administration, Cengage, Boston, 2013.

NOGUER PORTERO, M. C.: "La evaluación del desempeño", en DEL REY GUANTER, S. (dir.). Comentarios al Estatuto Básico del Empleado Público, La Ley, Madrid, 2008, pp. 303 a 326.

ORTEGA ÁLVAREZ, L. I. : "La función pública en el ordenamiento histórico italiano", Revista de Administración Pública 96, 1981, pp. 71 a 178.

PADILLA RUIZ, P.: Gestión del empleo público, Bosch, Barcelona, 2016.

PAREJO ALFONSO, L.: "La eficacia como principio jurídico de actuación de la Administración Pública», Documentación Administrativa 218-219, 1989 , pp. 15 a 66.

"La eficacia, principio de la actuación de la Administración», en Eficacia y Administración. Tres estudios, INAP, Madrid, 1995, pp. 89 a 152.

RECIO SÁEZ DE GUINOA, J. M. y FERNÁNDEZ-CABALLERO LAMANA, L.: "Líneas generales de la nueva ley de empleo público de Aragón", Revista Aragonesa de Administración Pública 13, 2011, pp.65 a 95. 
ROUBAN, L.: Le statut des fonctionnaires comme enjeu socio-historique, Revue Française d'Administration Publique, 132, 2009, pp. 673 a 687.

SALGADO VELO, J. y LUIS CABRAL, A.: «Evaluación del desempeño en la Administración Pública del Principado de Asturias: análisis de las propiedades psicométricas", Revista de psicología del trabajo y de las organizaciones/ Journal of work and organizational psychology 2, 2011, pp. 75 a 91.

WHITE, L.D., The Jacksonians, The Macmillan Co., New York, 1954.

WIESEL, D. S. y BUCKLEY, M. R.: «The evolution of the performance appraisal process", Journal of Management History, Vol. 4 Iss 3, 1998. 
LABURPENA: Enplegatu Publikoen Oinarrizko Estatutuak sartu zuen, estatu-mailan, enplegatu publikoen lanaren gaineko ebaluazioaren irudia. Hainbat herrialdetako administrazioan erabiltzen da tresna hori, eta, beste xede batzuen artean, enplegatuek erakundeari egiten dioten ekarpena neurtzea edo egon daitezkeen prestakuntza-premiak hautematea ahalbidetzen du. Ebaluazio hori Estatutuan sartzeak eta dauden administrazioen eremuan orokortzeak ondorio garrantzitsuak izan ditzake, bai langileei dagokienez (ordainsarien edo karreraren arloan), bai herritarrei dagokienez (administrazio-jardueraren hartzaileak diren heinean). Onartu eta hamar urtera, arau autonomiko gutxik garatu dituzte Estatutuak lanaren ebaluazioari eskaintzen dizkion agindu bakanak. Bestalde, funtzio publikoari buruzko legedi autonomikoetan, enplegatuen gainean hainbat eragin dituzten ebaluazio-sistema ezberdinak aurki daitezke. Ikerketa honetan bilduko ditugu.

GAKO HITZAK: Administrazio publikoko langileak. Lanaren gaineko ebaluazioa. Autonomia-erkidegoko zuzenbidea. Administrazio-antolamendua. Eraginkortasuna.

RESUMEN: El Estatuto Básico del Empleado Público introdujo a nivel estatal la figura de la evaluación del desempeño de los empleados públicos. Se trata de una herramienta utilizada en la Administración de diversos países que, entre otros fines, permite medir la aportación de los empleados a la organización o detectar posibles necesidades de formación. Su incorporación al Estatuto y su generalización en el ámbito de las distintas Administraciones puede tener relevantes consecuencias, tanto para los trabajadores (en materia de retribuciones o de carrera), como para la ciudadanía (destinataria de la actividad administrativa). Diez años después de su aprobación, son pocas las normas autonómicas que han desarrollado los escasos preceptos que el Estatuto dedica a la evaluación del desempeño. Por su parte, en las distintas legislaciones autonómicas sobre función pública, pueden encontrarse distintos sistemas de evaluación con diferentes efectos sobre los empleados que recopilamos a lo largo del presente estudio.

PALABRAS CLAVE: Empleados públicos. Evaluación del desempeño. Derecho autonómico. Organización administrativa. Eficacia.

ABSTRACT: The Basic Statue for Public Employees introduced the figure of performance assessment at the central state level. This is a tool employed by public administrations in several countries, which allows, among other goals, to measure the contribution of employees to the organization, or detect possible training necessities. The incorporation of this figure to the Statute, and its generalization to diverse public administrations, can have relevant consequences, both for the workers (in terms of their compensation and careers), and for the citizenship (the addressee of administrative activity). Ten years after its approval, few legal norms of autonomous communities have developed the small number 
of dispositions that the Statute contains regarding performance assessment. In the several legal systems of autonomous communities regarding public employment, diverse methods of performance assessment can be found, with different impact on employees, which we summarize in the present study.

KEYWORDS: Public Employees. Performance assessment. Autonomous communities law. Administrative organization. Effectiveness. 